\title{
Varying water deficit stress (WDS) tolerance in grain amaranths involves
}

\section{multifactorial shifts in WDS-related responses}

\author{
América Tzitziki González-Rodríguez ${ }^{1}$, Ismael Cisneros Hernández ${ }^{1}$, Norma A. Martínez-
} Gallardo $^{1}$, Erika Mellado-Mojica ${ }^{1}$, Mercedes López-Pérez ${ }^{1}$, Enrique Ramírez-Chavez ${ }^{1}$, Jorge Molina-Torres ${ }^{1}$ and John P. Délano-Frier ${ }^{1 *}$

emails: america.gonzalez@ira.cinvestav.mx; isamel.cisneros@ira.cinvestav.mx; nmartine@ira.cinvestav.mx; emellado@ira.cinvestav.mx; mlopez@ira.cinvestav.mx; eramirez@ira.cinvestav.mx; jmolina@ira.cinvestav.mx; jdelano@ira.cinvestav.mx

${ }^{1}$ Centro de Investigación y de Estudios Avanzados del I. P. N., Unidad Irapuato, Km 9.6 del Libramiento Norte Carretera Irapuato-León, C.P. 36821, Irapuato, Gto., México.

*To whom correspondence should be addressed:

John P. Délano-Frier, Biotechnology and Biochemistry Department, Centro de Investigación y de Estudios Avanzados del I. P. N., Unidad Irapuato, Km 9.6 del Libramiento Norte Carretera Irapuato-León, C.P. 36821, Irapuato, Gto., México. Telephone number: (52) 462623 9636; e-mail: jdelano@ira.cinvestav.mx

Date of submission: June 222017

Number of tables and figures: 10 figures, 6 tables, 8 supplementary figures and 3 supplementary tables.
Word count: 6486

Running title: Water stress tolerance in amaranth involves multiple factors 
28 Highlight: Differential water deficit stress tolerance in grain amaranths and their ancestor,

29 Amaranthus hybridus, is a multifactorial process involving various biochemical changes

30 and modified expression patterns of key stress-related genes.

31

32

33

34

35

36

37

38

39

40

41

42

43

44

45

46

47

48

49

50 


\section{Abstract}

In this study, water deficit stress (WDS)-tolerance in several cultivars of grain amaranth species (Amaranthus hypochondriacus [Ahypo], A. cruentus [Acru] and A. caudatus [Acau]), in addition to A. hybridus (Ahyb), an ancestral amaranth, was examined. Ahypo was the most WDS-tolerant species, whereas Acau and Ahyb were WDS-sensitive. Data revealed that the differential WDS tolerance observed was multifactorial. It involved increased proline and raffinose (Raf) in leaves and/ or roots. Higher foliar Raf coincided with induced Galactinol synthase 1 (AhGolS1) and Raffinose synthase (AhRafS) expression. Unknown compounds, possibly larger RFOs, also accumulated in leaves of WDS-tolerant amaranths, which had high Raf/ Verbascose ratios. Distinct nonstructural carbohydrate (NSC) accumulation patterns were observed in tolerant species under WDS and recovery, such as: i) high Hex/ Suc ratios in roots coupled to increased cell wall and vacuolar invertase and sucrose synthase activities; ii) a severer depletion of starch reserves; iii) lower NSC content in leaves, and iv) higher basal hexose levels in roots which further increased under WDS. WDS-marker gene expression patterns proposed a link between amaranth's WDS tolerance and abscisic acid-dependent signaling. Results obtained also suggest that AhTRE, AhTPS9, AhTPS11, AhGolS1 and AhRafS are reliable gene markers of WDS tolerance in amaranth.

Keywords: grain amaranth, water deficit stress tolerance, proline, raffinose family oligosaccharides, nonstructural carbohydrates, trahalose.

Abbreviations: ABA (abscisic acid), Ahypo (Amaranthus hypochondriacus), Acru (A. cruentus), Acau (A. caudatus), Ahyb (A. hybridus), CWI (cell wall invertase), CI (cytoplasmic invertase), Glu (glucose), Gol (galactinol), GolS (galactinol synthase), Fru (fructose), MWDS (moderate water deficit stress), NSC (nonstructural carbohydrate), Pro (proline), Raf (raffinose), RafS (raffinose synthase), RFO (Raffinose Family Oligosaccharides), Sta (stachyose), R (recovery), Suc (sucrose), RT (retention time), SuSy (sucrose synthase), SWDS (severe water-deficit stress), TF (transcription factor), T6P (trehalose-6-phosphate), TPS (trehalose-6-phosphate synthase), TPP (trehalose phosphate phosphatase), Tre (trehalose), TRE (trehalase), VI (vacuolar invertase), WDS (water deficit stress). 


\section{Introduction}

82 Plants have evolved to avoid, escape or tolerate stress conditions using numerous mechanisms that include several morphological, physiological and metabolic adaptations (Golldack et al., 2014). Plant drought and salt adaptation involves control of water flux and 85 cellular osmotic adjustment via the regulation of stomatal aperture, biosynthesis of osmoprotectants and reestablishment of the cellular redox status via the removal of reactive oxygen species (ROS) (Golldack et al., 2014). Gene expression is also profoundly modified upon salt and drought stress. Stress-related genes code for proteins involved in osmolyte biosynthesis, detoxifying processes and transport, as well as in regulatory processes. Transcription factors (TFs), protein kinases, and phosphatases are central players in the latter. Both abscisic acid (ABA)-dependent and ABA-independent signaling pathways are activated to cope with abiotic stress (Krasensky and Jonak, 2012; Golldack et al., 2014).

The accumulation of compatible solutes constitutes a protective mechanism employed by plants to ameliorate the damaging effects of drought and other abiotic stresses. This diverse group includes proline (Pro), soluble non-structural carbohydrates (NSCs; i.e., sucrose, glucose and fructose), and raffinose family oligosaccharides (RFOs), among others. They can accumulate in many plants in response to different stresses, and may perform roles other than osmoprotection, such as ROS scavenging or protein stabilization. Pro accumulation has also been found to promote plant recovery from drought stress (An et al., 2013). Starch can be rapidly mobilized to provide soluble sugars. Thus, starch catabolism is accelerated in response to salt drought and other stresses usually as an osmotic adjustment response via increased soluble NSCs accumulation (Castrillón-Arbeláez et al., 2012; Vargas et al., 2013; Reguera et al., 2013). These can maintain cell turgor or protect membranes and proteins from stress-related damage. Sucrose metabolism, via invertases, also regulates abiotic stresses responses by providing hexoses, as essential metabolites and signaling molecules (Ruan et al., 2012) or promoting heat shock protein accumulation (Liu et al., 2013). Likewise, glucose metabolism may prevent cell death via augmented reducing power and concomitant antioxidants biosynthesis (Bolouri-Moghaddam et al., 2010). On the other hand, RFOs are extensively distributed in higher plants, functioning in carbon (C) storage and redistribution. (Ayre et al., 2013). They are also known to accumulate during 
111

112

113

114

115

116

117

118

119

120

121

122

123

124

125

126

127

128

129

130

131

132

133

134

135

136

137

138

139

140

seed desiccation and/ or in leaves of plants subjected to various abiotic stresses, although their precise role in plant stress tolerance acquisition is not fully understood (Nishizawa et al., 2008; ElSayed et al., 2014). Biosynthesis of RFO originates from galactinol (Gol) generated from myo-inositol (MI) and UDP-galactose by Gol synthase (GolS). Gol subsequently acts as a galactose unit donor to Suc to generate raffinose (Raf), stachyose (Sta) and higher order RFOs, via their respective glycosyltransferases (Peterbauer and Richter, 2001).

Trehalose (Tre) is a non-reducing disaccharide present in trace amounts in most plants. It is presumably involved in the regulation of plant development and abiotic stress resistance. Thus, targeted manipulation of trehalose-6-phosphate (T6P), Tre's precursor, also accumulating in trace amounts in most plants, has been found to improve abiotic stress tolerance and yield in some crop plants (Figueroa and Lunn, 2016). This phosphorylated precursor is synthesized by trehalose-6-phosphate synthases (TPSs) and may be subsequently dephosphorylated to Tre by trehalose-6-phosphate phosphatases (TPPs). Tre itself may be hydrolyzed to two glucose moieties by trehalase (TRE) (Lunn et al., 2014). T6P's role as a sensor of $\mathrm{C}$ availability has been proposed to involve a negative interaction with sucrose non-fermenting related kinase-1 (SnRK1) a known inhibitor of plant growth (Liu et al., 2013; Delorge et al., 2014; Lunn et al., 2014; Tsai and Gazzarrini, 2014; Figueroa and Lunn, 2016).

The genus Amaranthus consist of 60-70 species. Some are consumed as vegetables or are used as a source of grain. The latter (Amaranthus hypochondriacus, A. cruentus, and A. caudatus) possess desirable agronomic characteristics and produce highly nutritional seeds. Moreover, they adapt easily to drought and poor soils (Caselato-Sousa and Amaya-Farfán, 2012). Domesticated grain amaranths presumably descend from wild A. hybridus, although their origin and taxonomic relationships are still uncertain (Sogbohossou and AchiganDako, 2014).

The physiological traits that enable amaranths to thrive in harsh conditions, such as drought, and be amenable for cultivation on marginal lands unsuitable for cereals, have been partly uncovered. In this work, we compared four amaranth species that differed in their tolerance to water-deficit stress (WDS) in order to identify common and/ or divergent 
141

142

143

144

145

146

147

148

149

150

151

152

153

154

155

156

157

158

159

160

161

162

163

164

165

166

167

168

169

responses to this condition. The changes in the expression, in leaves and roots, of RFObiosynthetic genes and of genes involved in Tre metabolism and signaling were also evaluated. The content of RFOs, NSCs and Pro as well as invertases, sucrose synthase and amylase activity was also determined. The combined results of this study demonstrated that the differential WDS tolerance detected in the amaranth species tested, was the result of a multifactorial response

\section{Materials and Methods}

\subsection{Plant material}

Three semi-domesticated grain amaranth species (A. hypochondriacus [Ahypo], A. cruentus [Acru] and A. caudatus [Acau]) (Sauer, 1967) together with an undomesticated vegetable amaranth (A. hybridus [Ahyb]), believed to be grain amaranths' ancestor (Stetter and Schmid, 2017), were employed in the greenhouse experiments here described. All plant materials were provided by Dr. Eduardo Espitia Rangel, INIFAP, México, curator of the Mexican amaranth germplasm collection. Approximately 3 week-old plants having 9-10 expanded leaves were employed for experimentation. These were grown in 1.3 L plastic pots containing $250 \mathrm{~g}$ of a general substrate in a conditioned growth chamber, as described previously (Délano-Frier et al., 2011). A total of 8 cultivars/ accessions of at least one of the above species was tested, as follows: Ahypo ("Gabriela", "Revancha" and "DGTA" cultivars); Acru ("Amaranteca", Dorada" and "Tarasca" cultivars), Acau (no classification available) and Ahyb (accession $\mathrm{N}^{\circ}$. 1330).

\subsection{Water-deficit (WDS) stress experiments}

All WDS experiments were performed in a commercial green house with zenithal and lateral type ventilation (Baticenital 850; ACEA S.A., Mexico) in May to August of 2015. The average temperatures in the greenhouse ranged between $15^{\circ} \mathrm{C}$ (night) and $38^{\circ} \mathrm{C}$ (day), with an average 55\% R.H. The experiments were performed under natural light and photoperiod $(\approx 1300 \mu \mathrm{E}, \geq 12 \mathrm{~h}$ light). An initial experiment was performed to screen the 8 cultivars/ accessions mentioned above for their tolerance to WDS. WDS was established by withholding watering for 7 or 10 days, time after which moderate to severe plant wilting was evident. WDS tolerance was scored by determining the leaf water potentials at the end 
170

171

172

173

174

175

176

177

178

179

180

181

182

183

184

185

186

187

188

189

190

191

192

193

194

195

196

197

198

199

of the WDS treatments and the percentage of recovery one day after normal watering was restored following stress (results not shown). This led to the selection of the 4 materials for subsequent experimentation which were the following: Ahypo (var. "Gabriela") and Acru (var. "Amaranteca"), classified as "WDS tolerant", and Acau and Ahyb, as "WDS susceptible".

Subsequently, two tandem experiments were performed in the above conditions to test WDS tolerance based on soil water depletion. Prior to the start of the WDS trials, each experimental $1.3 \mathrm{~L}$ pot was weighed individually until maximum soil water retention capacity (SWC) was attained. WDS trials were started when all pots were at $90 \%$ SWC. Control plants were kept in these conditions for the duration of the experiments, whereas WDS was established by withholding watering until the SWC in each pot reached either $30 \%$ SWC ("moderate WDS, [MWDS]") or 10\% SWC ("severe WDS, [SWDS]"). These stress levels were reached approximately 5-6 and 9-10 days after regular watering was withheld, respectively. An additional group of plants was re-watered after reaching $10 \%$ SWC and was allowed to recover for $24 \mathrm{~h}$ ("recovery", [R]). Weighing of the pots to determine water loss was done on a daily basis, taking care to ensure it was consistently done at approximately the same time of the day. Twelve plants having 10-to-12 expanded leaves were used per treatment. Once the desired conditions were reached, roots and leaves from 3 similarly treated plants were sampled and combined. Control plants were similarly sampled, generating four subsamples per experimental group. All pooled tissue samples were flash frozen in liquid $\mathrm{N}_{2}$ and stored at $-70^{\circ} \mathrm{C}$ until needed.

\subsection{Extraction of total RNA and gene expression analysis by RT-qPCR}

Quantitative gene expression analysis using SYBR Green detection chemistry (Bio-Rad, Hercules, CA, USA) was performed as described previously (Palmeros-Suárez et al., 2015). Primers design for the amplification of the pertinent amaranth gene transcripts employed a published methodology (Thornton and Basu, 2011) and was based on recently published genomic data (Clouse et al., 2016) (Table S1). Relative gene expression was calculated using the comparative cycle threshold method (Livak and Schmittgen, 2001) using the AhACT7, AhEF $1 a$ and AhßTub5 genes for data normalization.

\subsection{Determination of NSC and Pro}


200 Leaf and root samples collected from control plants, and from plants subjected to MWDS,

201 SWDS or R, were used to quantify soluble NSCs and Pro contents, according to Palmeros-

202 Suárez et al. (2015).

2032.5 Determination of RFOs by HPAEC-PAD

204 Identification and determination of RFOs content in leaf and root samples was performed

205 by High-Performance Anion-Exchange Chromatography with Pulsed Amperometric 206 Detection (HPAEC-PAD), according to Mellado-Mojica et al. (2016). All chemicals used 207 for the optimization of the chromatographic separation conditions and for quantitation were 208 acquired from Sigma (Sigma-Aldrich, St. Louis, MO, USA),). These were the following: 209 MI, Gol, Raf, Sta, and verbascose (Ver).

2102.6 Determination of trehalose by GC/MS and thin layer chromatography (TLC) analysis

211 Tre levels were determined by GC/ MS using a ion selective method as described 212 previously (Orona-Tamayo et al., 2013). RFO analysis by TLC was performed using 213 HPTLC silica gel 60 F254 plates as described previously (Waksmundzka-Hajnos et al., 214 2008).

2152.7 Determination of invertases, sucrose synthase and amylase activities

216 Vacuolar, cell wall, and cytoplasmic invertases and sucrose synthase (SuSy) activities were 217 determined as described in Wright et al. (1998). Amylase activity was determined 218 according to Bernfeld (1955). All assays were modified to fit a micro-plate format.

2192.8 Statistical analysis

220 All experiments were conducted using a randomized complete block design. One-way 221 ANOVAs were utilized to evaluate differences between treatment means. For ANOVAs 222 where the F test was significant at $P \leq 0.05$, the Tukey-Kramer test was applied. Statistical 223 analysis was performed with $\mathrm{R}$ software (Development Core Team, https://www.r224 project.org/).

\section{3. Results}


226

227

228

229

230

231

232

233

234

235

236

237

238

239

240

241

242

243

244

245

246

247

248

249

250

251

252

253

254

255

The initial screening to determine possible differences in WDS tolerance between amaranth species revealed that Ahypo cv. Gabriela, followed by Acru cv. Amaranteca were the most WDS tolerant species (with ca. $60 \%$ and $45 \%$ recovery after WDS, respectively). On the other hand, Acau was the most susceptible (with a 35\% recovery rate to MWDS but unable to tolerate SWDS). Interestingly, completely desiccated Ahyb plants recovered from SWDS after watering was restored (results not shown).

A gene expression analysis in roots and leaves of the four amaranth genotypes was performed next. These were originally detected in a previous grain amaranth transcriptomic analysis (Délano et al., 2011), and were later found to respond to severe defoliation in grain amaranth (Cisneros, 2016). Several genes involved in Tre biosynthesis and breakdown, including one class I TPS gene (AhTPS1), three TPP genes (AhTPPA, AhTPPD and $A h T P P I)$ and one TRE gene (AhTRE) were analyzed. Also included were several noncatalytic class II TPS genes (AhTPS5, AhTPS7, AhTPS8, AhTPS9, AhTPS10 and AhTPS11). Only the class I TPS gene (AhTPS-AHYPO 004431) and four additional AhTPP genes, annotated in the A. hypochondriacus genome (Clouse et al., 2016), were not included in this study, whereas all 6 class II TPS genes were incorporated. All genes were named according to the closest homology shown with their respective Arabidopsis thaliana orthologs (Supplementary Fig. S1-S3). Also included were four genes involved in RFOs biosynthesis (Gol synthase [AhGolS1 and AhGolS2], Raf synthase [AhRafS], and Sta synthase $[A h S t a S])$ and a number of sucrose non-fermenting related kinases similarly shown to be affected by severe defoliation in grain amaranth (SnRAK, SnRK1a, SnRK2.1 and SnRK2.2) (Cisneros, 2016). Finally, the expression of four ABA-related stress marker genes (AhRAB18, AhABI5, AhDREB2C and AhLEA14) were included as controls.

WDS had almost no effect on the expression of the class I AhTPS1 gene in leaves (Table 1A). Only limited induction was detected in Ahyb and Acau. Similarly, the expression of class II AhTPS5, AhTPS7 and AhTPS8 in leaves of all plants was predominantly unaffected by stress or downregulated. Downregulation of these genes by MWDS in Ahypo was prominent. In contrast, AhTPS11 responded strongly to WDS and R in practically all plants tested. This response was particularly evident during SWDS. The expression of the other two class II TPS genes was also induced chiefly during SWDS, although differences 
256

257

258

259

260

261

262

263

264

265

266

267

268

269

270

271

272

273

274

275

276

277

278

279

280

281

282

283

284

285

between species were observed in other conditions (Table 1B). Likewise, the TPP and TRE genes were, in general, unaffected or repressed by WDS in leaves. Noticeable exceptions were the induction, by WDS, of AhTPPD and AhTPPI, and the repression, in $\mathrm{R}$, of $A h T P P A$ and AhTPPD, in Ahypo. WDS also induced AhTPPA, AhTPPI and AhTPPD in Acru and Acau (Table 1C). Finally, AhTRE was exclusively induced by WDS in leaves of Ahypo (Table 1D).

The expression pattern of these genes changed in roots. The frequency with which they were induced in response to WDS or R was lower and their expression levels were reduced compared to those in leaves (Table 2). Thus, class I AhTPS1 was repressed in WDS-tolerant species and unaltered in the other two (Table 2A). Likewise to leaves, class II AhTPS5, AhTPS7 and AhTPS8 genes generally remained unchanged or were repressed by WDS and/ or R (Table 2B). AhTPS10, was also induced exclusively in Acru and Acau, whereas it was repressed by WDS in Ahyb. AhTPS9 was induced by SWDS and R in all species tested with the exception of Ahyb, whereas AhTPS11 was again induced universally by SWDS, but at lower levels. However, its expression in other conditions tested was more sporadic than in leaves. Importantly, the expression levels of AhTPS9 during SWDS was significantly higher in roots of Ahypo and Acru, in concordance with their superior WDS tolerance. Also noticeable, was the widespread induction of AhTPS9-AhTPS11 in Acau. Besides, the expression of all AhTPP genes tested was repressed or unaltered by WDS in roots (Table 2C), whereas AhTRE ceased to be induced in roots of Ahypo, similarly to the other species examined (Table 2D).

Tre levels were measured by GC-MS, considered more accurate than HPAEC (Quéro et al., 2013). The results show that a 2-to-3-fold Tre accumulation was induced by both MWDS, SWDS, and sometimes in R, in both leaves (Fig. 1A) and roots (Fig. 1B) of all amaranth species. However, the effect was more noticeable in roots and was stronger in WDSsusceptible species. Tre contents showed a poor correlation with the expression of Tre biosynthesis-related genes. This lack of synchronicity suggested that its accumulation may have involved a post-translational activation of class I TPS1 enzyme(s) (Delorge et al., 2015), an event that remains poorly understood (Rubio-Texeira et al., 2016). Tre accumulation could have also reflected the weak induction of Tre catabolism genes 
286

287

288

289

290

291

292

observed, similar to related studies that connected Tre accumulation with TRE inactivation (Goddijn et al., 1997; Müller et al., 2001).

WDS and $\mathrm{R}$ induced the expression of $A h S n R A K$ in leaves of WDS-susceptible plants and in roots of WDS-tolerant species. AhSnRKla expression remained practically unchanged except for sporadic down- or up-regulated events in leaves and roots. Conversely, $A h S n R K 2.1$ and $A h S n R K 2.2$ were negatively affected in leaves of WDS-tolerant plants but induced by WDS in AHyb. Their expression remained unaffected in roots (Supplementary Tables S2, S3).

Regarding RFO-biosynthesis genes, AhGolS1 and AhRafS were almost universally induced by WDS in amaranth leaves, whose expression tended to be highest during SWDS (Table 3). The induction of these genes was lower or returned to basal levels, in R. On the other hand, foliar expression of AhGolS2 was mostly unaffected by WDS. The expression of AhStaS, invariable in leaves of Ahypo and Ahyb, was intermittent in Acau and Acru.

AhGolS1 expression in roots of WDS-treated amaranth plants was intensely induced by SWDS, notably in Acru (Table 4). AhGolS1 expression in roots of Ahypo during SWDS was also high, being 1.8- to 3.6-fold higher than those detected in Acau and Ahyb, respectively. Thus, AhGolS1 expression pattern in roots of grain amaranth plants also coincided with their WDS tolerance. Conversely, AhGolS2 was almost universally induced in response to WDS in roots. Root $A h G o l S 2$ gene expression patterns in response to WDS were mirrored by those produced by the AhRafS and AhStaS genes, except for the occasional induction of the latter during R. The ca. 3- to 10-fold higher AhRafS expression levels detected in roots of Ahypo and Acru subjected to SWDS, compared to those in Acau and Ahyb, also agreed with their increased WDS tolerance.

The RFO accumulation pattern in leaves and roots (Fig. 2, 3) partially coincided the expression of RFO biosynthesis-related genes (Tables 3, 4). Raf accumulation in leaves could be likewise suggested as another contributing factor to the increased WDS tolerance observed in Ahypo and Acru. In contrast, practically no accumulation of Gol was detected in leaves of all species, irrespective of their treatment, suggesting an active utilization of this precursor for the synthesis of RFOs. On the other hand, MI content remained unaltered in leaves of Ahypo plants (Fig. 2A), but accumulated, particularly during SWDS, in Acru 
316

and Acau (Fig. 2B, C). Sta content was minimal in leaves of all species and changes were small and sporadic (Fig. 2A, B, D). Similarly Ver content in Ahypo and Acru (Fig. 2A, B) was modest and static. However, Ver levels increased to ca. 5-fold higher levels than controls in response to WDS in Acau and Ahyp (Fig. 2C, D). The above results suggest that Raf/ Ver ratios in leaves could constitute a marker of WDS tolerance in amaranth.

The root RFO results differed and had a lower correspondence with WDS tolerance in amaranth. Raf did not to accumulate in response to WDS in Ahypo and Acru (Fig. 3A, B). In Ahyb, Raf content fluctuations in roots were similarly erratic than those in leaves (Fig. 3D), whereas the ca. 2-fold higher basal Raf content in roots of Acau was drastically reduced by SWDS and R, similarly to Ahypo (Fig. 3C). SWDS conditions also induced the accumulation of MI in roots of Acru (Fig. 3B), while a significant increase occurred in Ahypo roots during R (Fig. 3A). Basal Gol contents in roots were ca. 2-fold lower than in leaves, and undetectable under certain conditions in roots of Ahyb (Fig. 3D). Sta contents remained low in roots and also showed a tendency to accumulate in response to SWDS. Contrary to leaves, root Sta accumulation was significantly increased by SWDS in all species tested (Fig. 3C). Likewise, Ver content increased in roots of all species in response to SWDS (Fig. 3A-D). Curiously, Ahypo and Ahyb accumulated almost identical Ver contents in response to WDS o R treatments (Fig. 3A, D).

The significantly higher foliar accumulation of Raf in Ahypo and Acru observed in response to MWDS and SWDS correlated with significantly augmented AhGolS1 and AhRafS expression levels (Table 3). In roots this association was not found, although these genes were expressed to ca. 10-fold higher levels than those detected in leaves under similar conditions (Table 4). The reason(s) why the intense induction of these genes did not translate into high contents of Raf and perhaps other RFOs in roots remains unknown. Contrarily, changes in AhStaS expression in response to WDS and R agreed with root Sta levels (Table 4; Fig. 3). However, this correspondence was not detected in leaves (Table 3; Fig. 2). The lack of coincidence between RFO content and their correspondent gene expression in some amaranth species could be explained by the possibility that these were being converted to putatively larger RFO, whose structure is yet to be determined. In this respect, several unknown compounds having longer retention times (RTs), and perhaps 

larger sizes, were detected (Supplementary Fig. S4-S7). Peaks with RTs of 16.1, 22.2 and 33.8 min were abundant in leaves WDS tolerant Ahypo and Acru, particularly in the former. Thus, they could be considered as contributors to WDS tolerance in these species. Contrarily, two peaks with RTs of ca. 16.8 and 21.1 min accumulated in roots of most treated plants, noticeably during SWDS and R. Curiously, both compounds were more abundant in WDS susceptible species. Thin-layer chromatography traces of both leaf and root crude extracts (Supplementary Fig. S8) show bands having differential intensity that could correspond to these unknown compounds, whose nature remains to be determined experimentally.

WDS marker genes were not uniformly expressed in treated plants; they varied depending on the treatment applied, organ examined and species. In leaves, AhABI5 and AhLEA14 were the only genes induced almost uniformly across species by WDS (Table 5A), although AhLEA14 expression was several-fold higher than AhABI5, and was induced in all conditions tested. Conversely, AhRAB18 was sporadically induced by WDS in Acau and Ahyb, whereas it remained practically unchanged in Ahypo and Acru. Contrariwise, $A h D R E B 2 C$ was induced by all treatments in Ahypo only. All marker genes were more intensely induced in roots (Table 5B), distinctly in Ahypo, Acru and Acau, whereas they remained mostly unaltered in Ahyb. Importantly, marker genes reached their highest expression in both leaves and roots of treated Ahypo plants, in correspondence with their superior WDS tolerance.

Pro levels were significantly higher in leaves of WDS-tolerant species, where the highest Pro contents accumulated in response to SWDS (Fig. 4A). Contrariwise, Pro accumulation in roots (Fig. 4B), did not vary much between amaranth species, where a significant increase was only observed in SWDS (although ca. 2.5-fold lower than in leaves). Significantly higher root Pro levels were also detected in MWDS and R in Ahyb, whereas the lowest Pro accumulation occurred in Acau. In contrast, NSCs content fluctuations in leaves and roots were consistent with the contrasting WDS tolerance observed between amaranth species. Thus, all NSCs were significantly lower in leaves of WDS-tolerant species, distinctly during SWDS (Figs. 5). In roots (Fig. 6), the NSC content variation in Ahypo was manifestly different. Thus Glu and Fru were the highest detected and Suc and 
starch levels the lowest. This occurred independently of the treatment analyzed. Lower hexose (Hex) content in leaves of Ahypo was in agreement with the WDS-unresponsive invertase activity observed (Fig. 7A-C), whereas consistently higher Glu and Fru contents in leaves of treated Acau and Ahyb plants coincided with increased cell wall invertase (CWI) (in most conditions tested; Fig. 7A), and to augmented vacuolar (VI) and cytoplasmic invertase activities (CI), mostly during R (Fig. 7A-C). In Acru, a gradual increase in Glu and Fru observed during WDS and R, could be attributed to an increased activity in all three invertases tested (Fig. 7A-C), mostly during SWDS. Nevertheless, its foliar Hex levels tended to be the lowest, together with Ahypo. Also intriguing was the Suc peak produced during SWDS in the latter species (Fig. 5A-C).

Conversely, the high Hex/ Suc ratio observed in roots of treated Ahypo plants was consistent with increased CWI and VI activity (Fig. 8A, B), and with a strong induction of SuSy activity in SWDS (Fig. 9). Lower SuSy activities, combined with repressed and/ or unchanged invertase activity in roots of Acau and Ahyb treated plants were consistent with their lower Hex/ Suc ratios. No SuSy activity was detected in leaves.

The above results indicated WDS had a different effect on the NSC content of leaves and roots in tolerant Ahypo and Acru, compared to susceptible Acau and Ahyb. Thus, leaves of tolerant amaranths tended to have lower Glu, Fru, and starch contents. The effect was drastic during SWDS, particularly for starch reserves, which were almost depleted (Fig. 5D, 6D). In contrast, constitutive Glu levels in roots of Ahypo plants were significantly higher than those in all others and increased significantly in R (Fig. 5A), whereas constitutively high Fru levels, further increased after WDS treatment (Fig. 5B). Amylolytic activity was almost uniformly induced in leaves of all treated plants (Fig. 10A), whereas is induction by all treatments was observed only in roots of Ahypo (Fig. 10B). This contrast suggests that additional starch degradation mechanisms contributed to the starch depletion observed in leaves and roots of WDS-tolerant amaranths (Grennan, 2006; Turesson et al., 2014).

\section{Discussion}

It was previously shown that the WDS response in Ahypo roots included the accumulation of osmolytes and increased levels of ROS scavenging and heat shock proteins, together with the induction of certain TFs (Huerta-Ocampo et al., 2011). Several other amaranth 
406

407

408

409

410

411

412

413

414

415

416

417

418

419

420

421

422

423

424

425

426

427

428

429

430

431

432

433

434

435

genes have been subsequently proposed as possible contributing factors to increased tolerance against several (a)abiotic stresses in grain amaranth, including an orphan gene (Massange-Sánchez et al., 2015), a gene with an unknown function domain (PalmerosSúarez et al., 2017) and various TF genes (Palmeros-Súarez et al., 2015; MassangeSánchez et al., 2016). The above genes were induced in grain amaranth by several stress conditions and frequently conferred stress tolerance when overexpressed in Arabidopsis plants.

The present study found, however, that WDS tolerance in grain amaranth varied within and between species. Ahypo and Acru tended to be tolerant, whereas Acau, an incompletely domesticated grain amaranth species (Stetter et al., 2017), and Ahyb, an undomesticated species presumed to be their ancestor (Stetter and Schmid, 2017), were susceptible. A battery of molecular and biochemical tests were employed to identify the bases of such difference. Changes in Tre and RSOs accumulation, as well as in the expression of related genes, together with modifications in $\mathrm{C}$ mobilization and in Pro content during WDS and in $\mathrm{R}$ were monitored. The general unresponsiveness of AhTPS1 and downstream targets (i.e., AhSnRK1) (Tables 1, 2; Supplementary Tables S2, S3) to WDS suggest that the role of T6P-related signaling was probably not a defining factor of WDS tolerance in grain amaranth. A similar prediction could be proposed for Tre (Fig. 1). This was partly in agreement with a study showing that Tre did not protect yeast cells from desiccation (Petitjean et al., 2015) and with others that found no link between increased Tre accumulation and stress tolerance. It was contradictory, however, to evidence connecting Tre accumulation with WDS tolerance (Figueroa and Lunn, 2016). Moreover, it may be suggested that increased foliar Tre levels, could have contributed to WDS susceptibility in Acau and Ahyb, similar to Arabidopsis tre null mutants that had increased Tre levels and were more sensitive to drought than WT plants (Van Houtte et al., 2013). Such effect was ascribed to a proposed link connecting Tre metabolism, stomatal conductance and variations in stomata's responsiveness to ABA.

Moreover, gene expression assays established a poor correlation between other Tre-related genes and increased WDS tolerance in Ahypo, except for a few exceptions: i) the general downregulation of foliar AhTPS5, of several other class II TPS genes during R, and of the 
436

437

438

439

440

441

442

443

444

445

446

447

448

449

450

451

452

453

454

455

456

457

458

459

460

461

462

463

464

465

AhTPPD and AhTPPI genes during WDS; ii) the high expression of AhTPS9 and AhTPS11 observed in leaves and roots (together with Acru) during SWDS, and iii) the induction of AhTRE during WDS (Tables 1, 2). Past studies have shown that class II TPS proteins have a differential sensitivity to Suc levels in plants (Schluepmann and Paul, 2009), which is important in the context of modified NSCs content observed in response to WDS in amaranth and other plants (Pinheiro and Chaves 2010). This property could explain the increased induction of the AhTPS9 and AhTPS11 in WDS-tolerant amaranth. However, the role of these genes in WDS amelioration remains to be determined. The above results were also consistent with the upregulation of TPS11 and TRE detected in stomatal guard cells of sucrose-treated Arabidopsis (Bates et al., 2012). Such coordinated effect was proposed to establish a connection between Tre metabolism, carbohydrate metabolism regulation, and stomatal movements via sugar sensing, and further supported the role of Tre in the regulation of stomatal behavior.

The significantly higher upregulation of AhTPS9 and AhTPS11 under SWDS in sucrosedepleted roots of Ahypo plants was also in accordance with studies showing that Suclimiting conditions, led a the induction of the AtTPS8-AtTPS11 genes in Arabidopsis (Baena-González et al., 2007, Ramon et al., 2009). Also relevant to the above results is the finding that the overexpression of OsTPS9 in rice significantly increased tolerance toward cold and salinity stress through its proposed association with OsTPS1 (Li et al., 2011; Zang et al., 2011). In contrast, the general WDS-unresponsiveness of class II TPS, TPP and TRE genes in Acau and Ahyb could have contributed to their WDS sensitivity.

Conversely, the differential Pro and RFOs accumulation observed during WDS and R strongly suggests their participation as WDS tolerance factors in amaranth. This proposal is supported by the known role of these compounds as osmoregulators, antioxidants, ROS scavengers, signaling molecules and/ or as C reservoirs for post-stress recovery (Reguera et al., 2013; ElSayed et al., 2014; Kaur et al., 2015; Bascuñán-Godoy et al., 2016).

WDS was also observed to influence the expression levels of RFO biosynthetic genes in a differential way. The differences observed between WDS tolerant and susceptible amaranths were mostly quantitative and were of importance in roots, where the expression AhGolS1 and AhRafS was significantly higher in WDS-tolerant species, especially under 
466

467

468

469

470

471

472

473

474

475

476

477

478

479

480

481

482

483

484

485

486

487

488

489

490

491

492

493

494

495

496

SWDS (Table 4). These results were consistent with findings in leaves of Coffea canephora clones with contrasting tolerance to WDS, where the expression of the CcGolS1 gene differed between drought-tolerant and -sensitive clones, being strongly repressed in the latter (dos Santos et al., 2015). Additionally, a related study in C. arabica reported that, similar to amaranth, the CaGolS1 isoform was highly responsive to WDS (dos Santos et al., 2011). Likewise, the results in amaranth agreed with several other studies showing that the expression of GolS genes was congruous with abiotic stress tolerance in Arabidopsis (Taji et al., 2002; Nishizawa et al., 2008) and in transgenic tobacco plants (Kim et al., 2008; Wang et al., 2009). However, similar to observations in C. canephora, higher expression levels of these genes in amaranth leaves and roots did not always coincide with an accumulation of their respective RFOs. Such was the case of Gol, whose amounts were decreased or were undetectable in leaves of Ahypo and in roots of both WDS-susceptible amaranths. Likewise, decreased or unchanged Raf root content in SWDS, and the accumulation of Sta and Ver in leaves of stressed amaranth plants, were contrary to their corresponding gene expression patterns.

Nevertheless, WDS tolerance and RFOs accumulation in amaranth were in agreement with high leaf and root contents of Raf under MWDS and to foliar accumulation MI, Gol and Raf under SWDS, in Ahypo and Acru, respectively. Interestingly, the observed MI buildup may have supplied additional osmoregulatory and antioxidant activity, as previously reported (Ishitani et al., 1996; Duan et al., 2012). Similar results were reported in Chenopodium quinoa, an amaranth close relative (Downie et al., 1997). Thus, an increase in MI and/ or Raf levels was observed in leaves of two contrasting C. quinoa genotypes subjected to WDS (Bascuñán-Godoy et al., 2016). However, contrary to Ahypo and Acru, Raf levels accumulated in $\mathrm{R}$, which, in quinoa, was proposed to act as a $\mathrm{C}$ reservoir utilized for post-stress recovery (Karner et al., 2004). Amaranth RFO accumulation patterns in response to WDS were also similar to those reported in a WDS tolerant alfalfa cultivar able to accumulate Raf and Gol in roots during stress (Kang et al., 2011). A greater accumulation of shoot flavonoids and isoflavonoids was also proposed to contribute to higher WDS in alfalfa. The latter was in accordance with a previous report showing that WDS induced the accumulation of betacyanins and the induction of betacyaninbiosynthetic genes in vegetative tissues of Ahypo cultivars (Casique-Arroyo et al., 2012). 
497

498

499

500

501

502

503

504

505

506

507

508

509

510

511

512

513

514

515

516

517

518

519

520

521

522

523

524

525

526

The observed accumulation of Sta and Ver in roots of WDS-stressed amaranth plants was similar to that reported in leaves of $C$. arabica (dos Santos et al., 2011), although it did not seem to affect WDS tolerance in amaranth. On the other hand, other results (Fig. S4-S9), suggest that putative RFOs with a higher degree of polymerization differentially accumulated in leaves of Ahypo and Acru and may have, therefore, contributed to their WDS tolerance. This possibility remains to be determined. Nevertheless, it was in agreement with dos Santos et al. $(2011,2015)$ who argued that the drought-related increase in Gol biosynthesis in coffee was funneled to the generation of larger stress-protective RFOs by unidentified glycosyltransferases.

On the other hand, WDS tolerance in Ahypo and Acru was also defined by significantly higher Pro contents in leaves, principally during SWDS. Significantly higher Pro amounts also accumulated in Ahypo leaves during MWDS (Fig. 4A). On the other hand, Pro accumulation in roots in response to SWDS was, in general, similar in all species (Fig. 4B). Likewise to the behavior observed in alfalfa (Kang et al., 2011), but contrary to the pattern reported in quinoa (Razzaghi et al., 2015; Bascuñán-Godoy et al., 2016), Pro levels declined during $\mathrm{R}$ in all species, except in roots of Ahyb. This display coincided with several studies reporting its rapid metabolism in order to provide $\mathrm{N}$ and reducing power during stress recovery processes (Hayat et al., 2012; Kaur et al., 2015). Conversely, the significantly higher Pro amounts additionally detected in Ahyb roots during R might partly explain the remarkable recovery observed when severely dehydrated Ahyb plants were rewatered. Pro accumulation was also found to be a contributing factor to WDS tolerance in quinoa (Razzaghi et al., 2015; Bascuñán-Godoy et al., 2016) and alfalfa (Kang et al., 2011).

The characteristic modifications in NSC contents that occur in plants under WDS, both in response to reduced photosynthesis and to the need to maintain water uptake and cell turgor (Seki et al., 2007; Pinheiro and Chaves, 2010) were also observed in amaranth. However, the distinct patterns observed between species suggested that they might have contributed to their different WDS tolerance. Thus, tolerance in Ahypo was associated with inherently low foliar starch levels than became even lower in stressed plants. On the other hand, it presented a basal high Hex/ Suc ratio in roots, which remained practically unchanged by 
527 posterior treatments and also underwent a strong depletion of starch levels during WDS and

$528 \mathrm{R}$. The above also suggest that WDS-responsive root CWI, VI, SuSy and amylase enzymes

529 may have been contributing factors to the WDS tolerance observed in Ahypo. Intermediate

530 Acru shared with Ahypo the strong stress-related depletion of starch reserves in both leaves

531 and roots, whereas sensitive Acau and Ahyb had NSC patterns that were essentially the

532 opposite of those observed in Ahypo. Previous reports showing that severe defoliation led

533 to a drastic reduction of $\mathrm{C}$ reserves and the induction of various sucroytic and amylolytic

534 enzyme genes (Cisneros, 2016; Castrillón Arbeláez et al., 2012), including two of the four

535 SuSy genes present in the grain amaranth genome (Clouse et al., 2016) advocate this

536 proposal.

537 The Ahypo NSC fluctuation observed in roots was consistent with the C flow from starch

538 and/ or Suc to Hex triggered as an osmotic adjustment response to WDS in rice and other

539 plants. It agreed, as well, with the increase in invertases and SuSy gene expression and

540 activity that led to an accumulation of Hex in rice plants subjected to WDS (Reguera et al.,

541 2013).

542 On the other hand, the opposite behavior was observed in WDS susceptible Acau and 543 Ahyb, in which Suc levels tended to increase and starch reserves were less severely 544 depleted during WDS and R. This supports the proposal that varying patterns of NSC 545 accumulation are an additional WDS-tolerance contributing factor in amaranth. However, 546 other aspects not explored in this study, such as fluctuations in $\mathrm{N}$ partitioning, have been 547 found to be conductive to WDS tolerance in closely related species, such as quinoa 548 (Bascuñán-Godoy et al., 2016).

549 Another evident difference detected between WDS-tolerant and WDS-susceptible 550 amaranths, was the variable expression of the ABA marker genes (Tables 5, 6). This 551 suggests that differences in $\mathrm{ABA}$ content and/ or sensitivity could be additional factors 552 contributing to the differential WDS tolerance observed in amaranth, as previously 553 described in alfalfa (Kang et al., 2011). In this respect, the general unresponsiveness to 554 WDS of the SnRK2 subgroup of genes analyzed in this study was intriguing 555 (Supplementary Tables S2, S3), considering that SnRK2 genes are considered to play an 
556 important role in stress amelioration, partly through their involvement in the ABA signaling

557 pathway (Liu et al., 2013; Lind et al., 2015)

558

559

560

561

562

563

564

565

566

567

568

569

570

571

572

573

574

575

576

577

578

579

580

581

582

583

584

In conclusion, this study revealed that differential WDS tolerance between grain amaranth species and leafy, undomesticated, Ahyb, was due to multiple factors. Contributing factors to the improved WDS tolerance observed in Ahypo and Acru, were augmented levels in leaves and/ or roots of Pro and Raf. The WDS-accumulation of Raf in leaves of these species was consistent with augmented AhGolS1 and AhRafS expression levels. Unknown compounds, possibly structurally related to RFOs, were also found to differentially accumulate in leaves of WDS-tolerant species. Additionally, high Raf/ Ver ratios in leaves were found to be a possible determinant of WDS tolerance in amaranth. Moreover, clearly contrasting NSC patterns of accumulation/ depletion in response to WDS and R were observed in leaves and roots of WDS-tolerant and WDS-susceptible amaranth plants. Thus, high Hex/ Suc ratio in roots correlated with superior WDS-tolerance in Ahypo, which was in accordance with the induced activity of CWI, VI and SuSy in response to WDS. A severer depletion of starch reserves, which coincided with significantly increased amylase activity in roots, together with lower soluble NSCs in leaves, also appeared to correlate with WDS-tolerance in amaranth. This, in addition to higher basal levels of Hex in roots of Ahypo, which became even higher in response to WDS. Also significant was the high expression levels of ABA-marker genes in Ahypo plants, which suggested that the WDS tolerance shown by this species could be linked to a higher responsiveness to ABA-related WDS-tolerance mechanisms. Finally, the induced expression of AhTRE expression in leaves and of AhTPS9, AhTPS11, AhGolS1 and AhRafS in roots could be employed as markers of WDS tolerance in amaranth.

\section{Supplementary data}

Fig. S1. Phylogenetic analysis of amaranth class I and II trehalose phosphate synthase proteins.

Fig. S2. Phylogenetic analysis of amaranth trehalose phosphate phosphatase proteins.

Fig. S3. Phylogenetic analysis of the amaranth trehalase protein. 
585

586

587

588

589

590

591

592

593

594

595

596

597

598

599

600

601

602

603

604

605

606

607

608

609

610
Fig. S4. Accumulation of unidentified RFO-like compounds during WDS and R in leaves of amaranth plants.

Fig. S5. Accumulation of unidentified RFO-like compounds during WDS and R in roots of amaranth plants subjected to WDS.

Fig. S6. TLC separation of soluble NSCs and RFOs accumulating in leaf and roots of amaranth plants subjected to WDS.

Fig. S7. HPAEC-PAD traces of Ahypo leaf extracts showing the presence of un-identified RFO-like compounds in control and stressed plants.

Fig. S8. HPAEC-PAD traces of Acau roots extracts showing the presence of un-identified RFO-like compounds in control and stressed plants.

Table S1. List of qPCR primers used in this study.

Table S2. Expression patterns of selected $S n R K 1$ and $S n R K 2$ genes in leaves of four amaranth species during WDS and R.

Table S3. Expression patterns of selected $S n R K 1$ and $S n R K 2$ genes in roots of four amaranth species during WDS and R.

\section{ACKNOWLEDGEMENTS}

Support by "La Coordinadora Nacional de las Fundaciones Produce A.C. (COFUPRO; grant DF00000940), and CONACyT, México (grants 339254 and 371475, to ATGR and $\mathrm{ICH}$, respectively) is acknowledged. The authors are also grateful for the support provided by México Tierra de Amaranto A. C., and The Deborah Presser-Velder Foundation. 


\section{REFERENCES}

612

613

614

615

616

617

618

619

620

621

622

623

624

625

626

627

628

629

630

631

632

633

634

635

636

637

638

639

640

641

642

643

644

645

646

647

648

An Y, Zhang M, Liu G, Han R, Liang Z. 2013. Proline accumulation in leaves of Periploca sepium via both biosynthesis up-regulation and transport during recovery from severe drought. PLoS ONE 8, e69942.

Ayre BG, Keller F, Turgeon R. 2003. Symplastic continuity between companion cells and the translocation stream: Long distance transport is controlled by retention and retrieval mechanisms in the phloem. Plant Physiology 131, 1518-1528.

Bascuñán-Godoy L, Reguera M, Abdel-Tawab YM, Blumwald E. 2016. Water deficit stress-induced changes in carbon and nitrogen partitioning in Chenopodium quinoa Willd. Planta 243, 591-603.

Bates GW, Rosenthal DM, Sun J, Chattopadhyay M, Peffer E, Yang J, Ort DR, Jones AM. 2012. A Comparative Study of the Arabidopsis thaliana guard-cell transcriptome and its modulation by sucrose. PLoS ONE 7, e49641.

Bernfeld P. 1955. Amylases, $\alpha$ and $\beta$. In: Colowick S, Kaplan N, eds. Methods in Enzymology 1. Academic Press, NY, 149-158.

Bolouri-Moghaddam M., Le Roy K, Xiang L, Rolland F, Van den Ende W. 2010. Sugar signalling and antioxidant network connections in plant cells. FEBS Journal 277, 2022-2037.

Caselato-Sousa VM, Amaya-Farfán J. 2012. State of knowledge on amaranth grain: a comprehensive review. Journal of Food Science 77, R93-R104.

Casique-Arroyo G, Martínez-Gallardo N, González de la Vara L, Délano-Frier JP. 2014. Betacyanin biosynthetic genes and enzymes are differentially induced by (a)biotic stress in Amaranthus hypochondriacus. PLoS ONE 9, e99012.

Castrillón-Arbeláez PA, Martínez-Gallardo N, Avilés Arnaut H, Tiessen A, DélanoFrier JP. 2012. Metabolic and enzymatic changes associated with carbon mobilization, utilization and replenishment triggered in grain amaranth (Amaranthus cruentus) in response to partial defoliation by mechanical injury or insect herbivory. BMC Plant Biology 12, 163.

Cisneros-Hernández I. 2016. Cambios en la expresión génica de reguladores maestros del metabolismo en respuesta a la defoliación severa en amaranto de grano durante el desarrollo. MSc Thesis, Cinvestav, Irapuato, México.

Clouse JW, Adhikary D, Page JT, Ramaraj T, Deyholos MK, Udall JA, Fairbanks DJ, Jellen EN, Maughan PJ. 2016. The amaranth genome: genome, transcriptome, and physical map assembly. The Plant Genome 9, 1-14.

Délano-Frier JP, Avilés-Arnaut H, Casarrubias-Castillo K, Casique-Arroyo G, Castrillón-Arbeláez PA, Herrera-Estrella L, Massange-Sánchez J, Martínez-Gallardo NA, Parra-Cota FI, Vargas-Ortiz E, et al. 2011. Transcriptomic analysis of grain amaranth (Amaranthus hypochondriacus) using 454 pyrosequencing: comparison with $A$. 
tuberculatus, expression profiling in stems and in response to biotic and abiotic stress. BMC Genomics 12, 363.

Delorge I, Janiak M, Carpentier S and Van Dijck P. 2014. Fine tuning of trehalose biosynthesis and hydrolysis as novel tools for the generation of abiotic stress tolerant plants. Frontiers in Plant Science 5, 147.

Delorge I, Figueroa CM, Feil R, Lunn JE, Van Dijck P. 2015. Trehalose-6-phosphate synthase 1 is not the only active TPS in Arabidopsis thaliana. Biochemical Journal 466, 283-290.

dos Santos TB, Budzinski IG, Marur CJ, Petkowicz CL, Pereira LF, Vieira LG. 2011. Expression of three galactinol synthase isoforms in Coffea arabica L. and accumulation of raffinose and stachyose in response to abiotic stresses. Plant Physiology and Biochemistry 49, 441-448.

dos Santos TB, De Lima RB, Nagashima GT, De Oliveira Petkowicz CL, CarpentieriPípolo V, Pereira LFP, Vieira LGE. 2015. Galactinol synthase transcriptional profile in two genotypes of Coffea canephora with contrasting tolerance to drought. Genetics and Molecular Biology 38, 182-190.

Downie SR, Katz-Downie DS, Cho K-J. 1997. Relationships in the Caryophyllales as suggested by phylogenetic analyses of partial chloroplast DNA ORF2280 homolog sequences. American Journal of Botany 84, 253-273.

Duan JZ, Zhang MH, Zhang HL, Xiong HY, Liu PL, Ali J, Li JJ, Li Z. 2012. OsMIOX, a myo-inositol oxygenase gene, improves drought tolerance through scavenging of reactive oxygen species in rice (Oryza sativa L.). Plant Science 196, 143-151.

EISayed AI, Rafudeen MS, Golldack D. 2014. Physiological aspects of raffinose family oligosaccharides in plants: Protection against abiotic stress. Plant Biology 16, 1-8.

Figueroa CM, Lunn JE. 2016. A tale of two sugars: trehalose 6-phosphate and sucrose. Plant Physiology 172, 7-27.

Golldack D, Li C, Mohan H, Probst N. 2014. Tolerance to drought and salt stress in plants: unraveling the signaling networks. Frontiers in Plant Science 5, 151.

Goddijn OJ, Verwoerd TC, Voogd E, Krutwagen RWHH, de Graaf PTHM, Poels J, van Dun K, Ponstein AS, Damm B, Pen J. 1997. Inhibition of trehalase activity enhances trehalose accumulation in transgenic plants. Plant Physiology 113, 181-190.

Grennan AK. 2006. Regulation of starch metabolism in Arabidopsis leaves. Plant Physiology 142, 1343-1345.

Hayat S, Hayat Q, Alyemeni MN, Wani AS, Pichtel J, Ahmad A. 2012. Role of proline under changing environments: A review. Plant Signaling \& Behavior 7, 1456-1466.

Ishitani M, Majumder AL, Bornhouser A, Michalowski CB, Jensen RG, Bohnert HJ. 1996. Coordinate transcriptional induction of myo-inositol metabolism during environmental stress. The Plant Journal 9, 537-548. 
Kang Y, Han Y, Torres-Jerez I, Wang M, Tang Y, Monteros M, Udvardi M. 2011. System responses to long-term drought and re-watering of two contrasting alfalfa varieties. The Plant Journal 68, 871-889.

Karner U, Peterbauer T, Raboy V, Jones DA, Hedley CL, Richter A. 2004. myoInositol and sucrose concentrations affect the accumulation of raffinose family oligosaccharides in seeds. Journal of Experimental Botany 55, 1981-1987.

Kaur G, Asthir B. 2015. Proline: a key player in plant abiotic stress tolerance. Biologia Plantarum 59, 609-619.

Kim MS, Cho SM, Kang EY, Im YJ, Hwangbo H, Kim YC, Ryu CM, Yang KY, Chung GC and Cho BH. 2008. Galactinol is a signaling component of the induced systemic resistance caused by Pseudomonas chlororaphis O6 root colonization. Molecular Plant-Microbe Interactions 12, 1643-1653.

Krasensky J, Jonak C. 2012. Drought, salt, and temperature stress-induced metabolic rearrangements and regulatory networks. Journal of Experimental Botany 63, 1593-1608.

Li HW, Zang BS, Deng XW, Wang XP. 2011. Overexpression of the trehalose-6phosphate synthase gene OsTPS1 enhances abiotic stress tolerance in rice. Planta 234, 1007-1018.

Lind C, Dreyer I, López-Sanjurjo EJ, von Meyer K, Ishizaki K, Kohchi T, Lang D, Zhao Y, Kreuzer I, Al-Rashied KAS, et al. 2015. Stomatal guard cells co-opted an ancient ABA-dependent desiccation survival system to regulate stomatal closure. Current Biology 25, 928-935.

Liu Y-H, Offler CE, Ruan Y-L. 2013. Regulation of fruit and seed response to heat and drought by sugars as nutrients and signals. Frontiers in Plant Science 4, 282.

Livak KJ, Schmittgen TD. 2001 Analysis of relative gene expression data using real-time quantitative PCR and the $2^{-\Delta \Delta \mathrm{Ct}}$ method. Methods 25, 402-408.

Lunn JE, Delorge I, Figueroa CM, Van Dijck P, Stitt M. 2014. Trehalose metabolism in plants. The Plant Journal 79, 544-567.

Massange-Sanchez JA, Palmeros-Suarez PA, Martinez-Gallardo NA, CastrillonArbeláez PA, Avilés-Arnaut H, Alatorre-Cobos F, Tiessen A, Délano-Frier JP. 2015. The novel and taxonomically restricted Ah24 gene from grain amaranth (Amaranthus hypochondriacus) has a dual role in development and defense. Frontiers in Plant Science 6, 602.

Massange-Sánchez JA, Palmeros-Suaárez PA, Espitia-Rangel E, Rodríguez-Arévalo I, Sánchez-Segura L, Martínez-Gallardo NA, Alatorre-Cobos F, Tiessen A, Délano-Frier JP. 2016. Overexpression of grain amaranth (Amaranthus hypochondriacus) AhERF or AhDOF transcription factors in Arabidopsis thaliana increases water deficit- and salt-stress tolerance, respectively, via contrasting stress-amelioration mechanisms. PLoS ONE 11, e0164280. 
Mellado-Mojica E, González de la Vara LE, López MG. 2016. Fructan active enzymes (FAZY) activities and biosynthesis of fructooligosaccharides in the vacuoles of Agave tequilana Weber Blue variety plants of different age. Planta 245, 265-281.

Müller J, Aeschbacher RA, Wingler A, Boller T, Wiemken A. 2001. Trehalose and trehalase in Arabidopsis. Plant Physiology 125, 1086-1093.

Nishizawa A, Yabuta Y, Shigeoka S. 2008. Galactinol and raffinose constitute a novel function to protect plants from oxidative damage. Plant Physiology 147, 1251-1263.

Orona-Tamayo D, Wielsch N, Escalante-Pérez M, Svatos A, Molina-Torres J, Muck A, Ramirez-Chávez E, Ádame-Alvarez RM, Heil M. 2013. Short-term proteomic dynamics reveal metabolic factory for active extrafloral nectar secretion by Acacia cornigera ant-plants. The Plant Journal 73, 546-554.

Palmeros-Suárez PA, Massange-Sánchez JA, Martínez-Gallardo NA, Montero-Vargas JM, Gómez-Leyva JF, Délano-Frier JP. 2015. The overexpression of an Amaranthus hypochondriacus NF-YC gene modifies growth and confers water deficit stress resistance in Arabidopsis. Plant Science 240, 25-40.

Palmeros-Suárez PA, Massange-Sánchez JA, Sánchez-Segura L, Martínez-Gallardo NA, Espitia Rangel E, Gómez-Leyva JF, Délano-Frier JP. 2017. AhDGR2, an amaranth abiotic stress-induced DUF642 protein gene, modifies cell wall structure and composition and causes salt and ABA hyper-sensibility in transgenic Arabidopsis. Planta 245, 623-640.

Pinheiro C, Chaves MM. 2010. Photosynthesis and drought: can we make metabolic connections from available data? Journal of Experimental Botany 62, 869-882.

Quéro A, Béthencourt L, Pilard S, Fournet A, Guillot X, Sangwan RS, Boitel-Conti M, Courtois J, Petit E. 2013. Trehalose determination in linseed subjected to osmotic stress. HPAEC-PAD analysis: an inappropriate method. Physiologia Plantarum 147, 261 269.

Peterbauer T, Richter A. 2001. Biochemistry and physiology of raffinose family oligosaccharides and galactosyl cyclitols in seeds. Seed Science Research 11, 185-197.

Petitjean M, Teste MA, François JM, Parrou JL. 2015. Yeast tolerance to various stresses relies on the Trehalose-6P Synthase (Tps1) protein, not on trehalose. Journal of Biological Chemistry 290, 16177-16190.

Razzaghi F, Jacobsen S-E, Jensen CR, Andersen MN. 2015. Ionic and photosynthetic homeostasis in quinoa challenged by salinity and drought-mechanisms of tolerance. Functional Plant Biology 42, 136-148.

Ramon M, De Smet I, Vandesteene L, Naudts M, Leyman B, Van Dijck P, Rolland F Beeckman T, Thevelein JM. 2009. Extensive expression regulation and lack of heterologous enzymatic activity of the Class II trehalose metabolism proteins from Arabidopsis thaliana. Plant Cell \& Environment 32, 1015-1032.

Reguera M, Peleg Z, Abdel-Tawab YM, Tumimbang EB, Delatorre CA, Blumwald E. 2013. Stress-induced cytokinin synthesis increases drought tolerance through the 
coordinated regulation of carbon and nitrogen assimilation in rice. Plant Physiology 163, 1609-1622.

Rubio-Texeira M, Van Zeebroeck G, Thevelein JM. 2016. Trehalose metabolism: Enzymatic pathways and physiological functions. In: Hoffmeister D, ed. The Mycota III. Biochemistry and Molecular Biology. Springer International Publishing, 191-277.

Sauer JD. 1967. The grain amaranths and their relatives: A revised taxonomic and geographic survey. Annals of the Missouri Botanical Garden 54, 103-137.

Schluepmann H, Paul M. 2009. Trehalose metabolites in Arabidopsis-elusive, active and central. The Arabidopsis Book, American Society of Plant Biologists, e0122 doi: 10.1199/tab.0122

Seki M, Umezawa T, Urano K, Shinozaki K. 2007. Regulatory metabolic networks in drought stress responses. Current Opinion in Plant Biology 10, 296-302.

Sogbohossou OED, Achigan-Dako EG. 2014. Phenetic differentiation and use-type delimitation in Amaranthus spp. from worldwide origins. Scientia Horticulturae 178, 31-42.

Stetter MG, Schmid KJ. 2017. Analysis of phylogenetic relationships and genome size evolution of the Amaranthus genus using GBS indicates the ancestors of an ancient crop. Molecular Phylogenetics and Evolution 109, 80-92.

Stetter MG, T Müller, Schmid KJ. 2017. Genomic and phenotypic evidence for an incomplete domestication of South American grain amaranth (Amaranthus caudatus). Molecular Ecology 26, 871-886.

Thornton B, Basu C. 2011. Real-time PCR (qPCR) primer design using free online software. Biochemistry and Molecular Biology Education 39, 145-154.

Taji T, Ohsumi C, Iuchi S, Seki M, Kasuga M, Kobayashi M, Yamaguchi-Shinozaki K, Shinozaki K. 2002. Important roles of drought- and cold-inducible genes for galactinol synthase in stress tolerance in Arabidopsis thaliana. The Plant Journal 29, 417-426.

Turesson H, Andersson M, Marttila S, Thulin I, Hofvander P. 2014. Starch biosynthetic genes and enzymes are expressed and active in the absence of starch accumulation in sugar beet tap-root. BMC Plant Biology 14, 104.

Tsai AY-L, Gazzarrini S. 2014. Trehalose-6-phosphate and SnRK1 kinases in plant development and signaling: the emerging picture. Frontiers in Plant Science 5, 119.

Van Houtte H, Vandesteene L, López-Galvis L, Lemmens L, Kissel E, Carpentier S, Feil R, Avonce N, Beeckman T, Lunn JE, et al. 2013. Overexpression of the trehalase gene AtTRE1 leads to increased drought stress tolerance in Arabidopsis and is involved in abscisic acid-induced stomatal closure. Plant Physiology 161, 1158-1171.

Vargas-Ortiz E, Espitia-Rangel E, Tiessen A, Délano-Frier JP. 2013. Grain amaranths are defoliation tolerant crop species capable of utilizing stem and root carbohydrate reserves to sustain vegetative and reproductive growth after leaf loss. PLoS ONE 8, e67879. 
802 Waksmundzka-Hajnos M, Sherma J, Kowalska T. 2008. Thin Layer Chromatography in 803 Phytochemistry. Chromatographic Science Series 99. CRC Press LLC.

804 Wang Z, Zhu Y, Wang L, Liu X, Liu Y, Phillips J and Deng X. 2009. A WRKY

805 transcription factor participates in dehydration tolerance in Boea hygrometrica by binding 806 to the W-box elements of the galactinol synthase (BhGolS1) promoter. Planta 230, 11558071166.

808 Wright DP, Scholes JD, Read DJ. 1998. Effects of VA mycorrhizal colonization on 809 photosynthesis and biomass production of Trifolium repens L. Plant Cell \& Environment $810 \quad 21,209-216$.

811 Zang B, Li H, Li W, Deng XW, Wang X. 2011. Analysis of trehalose-6-phosphate 812 synthase (TPS) gene family suggests the formation of TPS complexes in rice. Plant 813 Molecular Biology 76, 507-522.

814

815

816

817

818

819

820

821

822

823

824

825

826

827

828

829 
831 Figure 1. Trehalose content was quantified by GC/ MS in (A) leaf and (B) root extracts of 832 four species of amaranth plants (i. e., Amaranthus hypochondriacus [Ahypo], A. cruentus 833 [Acru], A. caudatus [Acau] and A. hybridus [Ahyb]) growing in optimal conditions (Op), 834 subjected to moderate or severe water deficit stress (MWDS and SWDS, respectively) or 835 allowed to recover from SWDS by restoring watering for 1 day (R).or severe and 1 day 836 after normal watering was restored (R). Different letters over the bars represent statistically 837 significant differences at $P \leq 0.05$ (Tukey Kramer test). Bars and error bars indicate mean 838 values and ES, respectively ( $n=3$ pools of four plants each). The results shown are those 839 obtained from a representative experiment that was repeated in the spring-summer and 840 summer-autumn seasons of 2014, respectively, with similar results.

841 Figure 2. Raffinose family oligosaccharides (RFOs) were quantified by HPAEC-PAD in 842 leaf extracts of four species of amaranth plants: (A) Amaranthus hypochondriacus [Ahypo], 843 (B) A. cruentus [Acru], (C) A. caudatus [Acau], and (D) A. hybridus [Ahyb]) growing in 844 optimal conditions (Op; empty bars), subjected to moderate (M) or severe (S) water deficit 845 stress (gray and black bars respectively) or allowed to recover from S, 1 day after normal 846 watering was restored (R; striped bars). The RFOs and their respective precursors analyzed were myo-inositol (MI), galactinol (Gol), raffinose (Raf), staquiose (Sta) and verbascose

848 (Ver). Different letters over the bars represent statistically significant differences at $P \leq$ 8490.05 (Tukey Kramer test). Bars and error bars indicate mean values and ES, respectively (n $850=3$ pools of four plants each). The results shown are those obtained from a representative 851 experiment that was repeated in the spring-summer and summer-autumn seasons of 2014, 852 respectively, with similar results.

853 Figure 3. Raffinose family oligosaccharides (RFOs) were quantified by HPAEC-PAD in 854 root extracts of four species of amaranth plants: (A) Amaranthus hypochondriacus 855 [Ahypo], (B) A. cruentus [Acru], (C) A. caudatus [Acau], and (D) A. hybridus [Ahyb]) 856 growing in optimal conditions (Op; empty bars), subjected to moderate (M) or severe (S) 857 water deficit stress (gray and black bars respectively) or allowed to recover from S, 1 day 858 after normal watering was restored (R; striped bars). The RFOs and their respective 859 precursors analyzed were myo-inositol (MI), galactinol (Gol), raffinose (Raf), staquiose 
860

861

862

863

864

865

866

867

868

869

870

871

872

873

874

875

876

877

878

879

880

881

882

883

884

885

886

887

888

889

(Sta) and verbascose (Ver). Different letters over the bars represent statistically significant differences at $P \leq 0.05$ (Tukey Kramer test). Bars and error bars indicate mean values and ES, respectively ( $n=3$ pools of four plants each). The results shown are those obtained from a representative experiment that was repeated in the spring-summer and summerautumn seasons of 2014, respectively, with similar results.

Figure 4. Proline content quantified in vitro in (A) leaf and (B) root extracts of four species of amaranth plants (i. e., Amaranthus hypochondriacus [Ahypo], A. cruentus [Acru], A. caudatus [Acau] and A. hybridus [Ahyb]) growing in optimal conditions (Op; empty bars), subjected to moderate $(\mathrm{M})$ or severe $(\mathrm{S})$ water deficit stress (gray and black bars respectively) or allowed to recover from $\mathrm{S}, 1$ day after normal watering was restored (R; striped bars). Different letters over the bars represent statistically significant differences at $P \leq 0.05$ (Tukey Kramer test). Bars and error bars indicate mean values and ES, respectively ( $n=3$ pools of four plants each). The results shown are those obtained from a representative experiment that was repeated in the spring-summer and summer-autumn seasons of 2014, respectively, with similar results.

Figure 5. Non-structural carbohydrates (Glucose [Glu], Fructose [Fru], Sucrose [Suc] and starch) content quantified in vitro in leaves of four species of amaranth plants (i. e., Amaranthus hypochondriacus [Ahypo; thick continuous line], A. cruentus [Acru; thin continuous line], A. caudatus [Acau; short dash line] and A. hybridus [Ahyb; long chain line]) growing in optimal conditions (Op), subjected to moderate (M) or severe $(\mathrm{S})$ water deficit stress, or allowed to recover from S, 1 day after normal watering was restored (R). Different letters over the lines represent statistically significant differences at $P \leq 0.05$ (Tukey Kramer test). Bars and error bars indicate mean values and ES, respectively ( $\mathrm{n}=3$ pools of four plants each). The results shown are those obtained from a representative experiment that was repeated in the spring-summer and summer-autumn seasons of 2014, respectively, with similar results.

Figure 6. Non-structural carbohydrates (Glucose [Glu], Fructose [Fru], Sucrose [Suc] and starch) content quantified in vitro in roots of four species of amaranth plants (i. e., Amaranthus hypochondriacus [Ahypo; thick continuous line], A. cruentus [Acru; thin continuous line], A. caudatus [Acau; short dash line] and A. hybridus [Ahyb; long chain 
890

891

892

893

894

895

896

897

898

899

900

901

902

903

904

905

906

907

908

909

910

911

912

913

914

915

916

917

918

line]) growing in optimal conditions (Op), subjected to moderate (M) or severe (S) water deficit stress, or allowed to recover from S, 1 day after normal watering was restored (R). Different letters over the lines represent statistically significant differences at $P \leq 0.05$ (Tukey Kramer test). Bars and error bars indicate mean values and ES, respectively ( $\mathrm{n}=3$ pools of four plants each). The results shown are those obtained from a representative experiment that was repeated in the spring-summer and summer-autumn seasons of 2014, respectively, with similar results.

Figure 7. (A) Cell wall invertase (CWI), (B) vacuolar invertase VI), and (C) neutral cytoplasmic invertase (CI) activities determined in vitro in leaf extracts of four species of amaranth plants: Amaranthus hypochondriacus [Ahypo], A. cruentus [Acru], (C), A. caudatus [Acau], and (D) A. hybridus [Ahyb], growing in optimal conditions (Op; empty bars), subjected to moderate (M) or severe (S) water deficit stress (gray and black bars respectively) or allowed to recover from S, 1 day after normal watering was restored (R; striped bars). Different letters over the bars represent statistically significant differences at $P \leq 0.05$ (Tukey Kramer test). Bars and error bars indicate mean values and ES, respectively ( $n=3$ pools of four plants each). The results shown are those obtained from a representative experiment that was repeated in the spring-summer and summer-autumn seasons of 2014, respectively, with similar results.

Figure 8. (A) Cell wall invertase, (B) vacuolar invertase, and (C) neutral cytoplasmic invertase activities determined in vitro in root extracts of four species of amaranth plants: Amaranthus hypochondriacus (Ahypo), A. cruentus (Acru), A. caudatus (Acau), and A. hybridus (Ahyb), growing in optimal conditions (Op; empty bars), subjected to moderate (M) or severe (S) water deficit stress (gray and black bars respectively) or allowed to recover from S, 1 day after normal watering was restored (R; striped bars). Different letters over the bars represent statistically significant differences at $P \leq 0.05$ (Tukey Kramer test). Bars and error bars indicate mean values and ES, respectively $(n=3$ pools of four plants each). The results shown are those obtained from a representative experiment that was repeated in the spring-summer and summer-autumn seasons of 2014, respectively, with similar results. 
919 Figure 9. Sucrose synthase determined in vitro in root extracts of four species of amaranth

920 plants: Amaranthus hypochondriacus (Ahypo), A. cruentus (Acru), A. caudatus (Acau), and

921 A. hybridus (Ahyb), growing in optimal conditions (Op; empty bars), subjected to moderate

922 (M) or severe (S) water deficit stress (gray and black bars respectively) or allowed to

923 recover from S, 1 day after normal watering was restored (R; striped bars). Different letters

924 over the bars represent statistically significant differences at $P \leq 0.05$ (Tukey Kramer test).

925 Bars and error bars indicate mean values and ES, respectively $(n=3$ pools of four plants

926 each). The results shown are those obtained from a representative experiment that was

927 repeated in the spring-summer and summer-autumn seasons of 2014, respectively, with

928 similar results.

929 Figure 10. Amylase activity quantified in vitro in (A) leaf and (B) root extracts of four 930 species of amaranth plants (i. e., Amaranthus hypochondriacus [Ahypo], A. cruentus 931 [Acru], A. caudatus [Acau] and A. hybridus [Ahyb]) growing in optimal conditions (Op; 932 empty bars), subjected to moderate (M) or severe (S) water deficit stress (gray and black 933 bars respectively) or allowed to recover from $\mathrm{S}, 1$ day after normal watering was restored 934 (R; striped bars). Different letters over the bars represent statistically significant differences 935 at $P \leq 0.05$ (Tukey Kramer test). Bars and error bars indicate mean values and ES, 936 respectively ( $n=3$ pools of four plants each). The results shown are those obtained from a 937 representative experiment that was repeated in the spring-summer and summer-autumn 938 seasons of 2014, respectively, with similar results. 
bioRxiv preprint doi: https://doi.org/10.1101/153577; this version posted June 21, 2017. The copyright holder for this preprint (which was not certified by peer review) is the author/funder, who has granted bioRxiv a license to display the preprint in perpetuity. It is made available under aCC-BY-NC-ND 4.0 International license.

948

949

950

951

952

953

954

955 


\begin{tabular}{|c|c|c|c|c|c|c|c|c|c|c|c|c|}
\hline \multirow[t]{2}{*}{ Gene } & \multicolumn{3}{|c|}{ A. hypochondriacus } & \multicolumn{3}{|c|}{ A. cruentus } & \multicolumn{3}{|c|}{ A. caudatus } & \multicolumn{3}{|c|}{ A. hybridus } \\
\hline & M & $\mathrm{S}$ & $\mathrm{R}$ & $\mathrm{M}$ & $\mathrm{S}$ & $\mathrm{R}$ & $\mathrm{M}$ & $\mathrm{S}$ & $\mathrm{R}$ & M & $\mathrm{S}$ & $\mathrm{R}$ \\
\hline AhTPS1 & 1.348 & 1.088 & 0.886 & 0.764 & 0.788 & 0.899 & 1.100 & 1.205 & 2.532 & 1.315 & 1.704 & 3.030 \\
\hline AhTPS5 & 0.233 & 0.268 & 0.272 & 0.552 & 0.526 & 0.343 & 0.664 & 0.606 & 0.645 & 0.423 & 0.536 & 0.638 \\
\hline AhTPS7 & 0.498 & 0.768 & 0.748 & 0.879 & 1.208 & 0.806 & 0.673 & 1.172 & 2.245 & 0.659 & 1.076 & 1.199 \\
\hline AhTPS8 & 0.250 & 0.902 & 0.235 & 0.967 & 0.896 & 0.711 & 1.076 & 1.835 & 1.621 & 0.386 & 0.827 & 0.974 \\
\hline AhTPS9 & 0.796 & 2.917 & 0.287 & 0.893 & 2.454 & 0.781 & 2.045 & 2.715 & 2.832 & 1.115 & 2.136 & 1.021 \\
\hline AhTPS10 & 0.291 & 1.016 & 0.264 & 1.890 & 2.589 & 6.992 & 2.382 & 1.262 & 2.892 & 0.438 & 1.651 & 1.154 \\
\hline AhTPS11 & 5.006 & 17.995 & 1.449 & 2.052 & 3.522 & 1.530 & 3.650 & 17.420 & 2.927 & 5.047 & 23.795 & 2.449 \\
\hline AhTPPA & 0.515 & 1.121 & 1.971 & 1.189 & 0.856 & 0.534 & 1.170 & 1.514 & 1.054 & 0.751 & 1.491 & 1.083 \\
\hline$A h T P P D$ & 0.334 & 0.186 & 2.972 & 1.579 & 0.824 & 0.730 & 1.556 & 0.876 & 0.580 & 0.532 & 1.318 & 1.948 \\
\hline$A h T P P I$ & 0.297 & 0.279 & 0.769 & 1.022 & 0.591 & 0.369 & 0.951 & 1.573 & 1.062 & 0.628 & 1.176 & 1.016 \\
\hline$A h T R E$ & 2.047 & 2.170 & 1.276 & 0.583 & 0.324 & 0.474 & 0.562 & 0.643 & 1.143 & 0.996 & 0.716 & 0.987 \\
\hline
\end{tabular}

Table 1. Relative expression values ${ }^{1}$ of genes involved in trehalose synthesis and degradation in leaves of four Amaranthus species subjected to two levels of water-deficit stress (moderate $[\mathrm{M}]$ and severe $[\mathrm{S}]$ ) and to subsequent recovery $([\mathrm{R}]$ ). Induced (normalized expression values $\geq 2.0$; in normal text) and repressed (normalized expression values $\leq 0.5$; in italicized text) expression values are emphasized in bold. 


\begin{tabular}{|c|c|c|c|c|c|c|c|c|c|c|c|c|}
\hline \multirow[t]{2}{*}{ Gene } & \multicolumn{3}{|c|}{ A. hypochondriacus } & \multicolumn{3}{|c|}{ A. cruentus } & \multicolumn{3}{|c|}{ A. caudatus } & \multicolumn{3}{|c|}{ A. hybridus } \\
\hline & M & $S$ & $\mathrm{R}$ & M & $\mathrm{S}$ & $\mathrm{R}$ & M & $\mathrm{S}$ & $\mathrm{R}$ & M & $\mathrm{S}$ & $\mathrm{R}$ \\
\hline AhTPS1 & 0.648 & 0.783 & 0.259 & 0.388 & 1.162 & 0.314 & 0.653 & 0.639 & 1.013 & 1.272 & 1.265 & 0.565 \\
\hline AhTPS5 & 1.463 & 0.523 & 1.314 & 0.833 & 0.684 & 0.922 & 0.911 & 0.775 & 1.615 & 0.423 & 0.294 & 1.473 \\
\hline AhTPS7 & 0.470 & 0.935 & 2.427 & 0.481 & 0.977 & 1.440 & 0.621 & 0.635 & 1.444 & 0.817 & 0.668 & 0.841 \\
\hline AhTPS8 & 1.715 & 0.715 & 0.939 & 0.713 & 0.991 & 0.760 & 1.877 & 1.114 & 1.478 & 0.384 & 0.285 & 0.616 \\
\hline AhTPS9 & 1.371 & 2.206 & 1.549 & 1.004 & 3.402 & 1.535 & 1.392 & 1.836 & 1.634 & 0.397 & 1.706 & 0.466 \\
\hline AhTPS10 & 0.536 & 0.810 & 0.695 & 1.154 & 2.562 & 0.868 & 1.321 & 1.512 & 2.212 & 0.325 & 0.356 & 0.888 \\
\hline AhTPS11 & 1.189 & 6.624 & 1.202 & 0.662 & 8.619 & 2.289 & 1.631 & 4.945 & 3.003 & 0.614 & 3.490 & 0.570 \\
\hline AhTPPA & 0.920 & 0.705 & 0.250 & 0.640 & 0.850 & 0.706 & 0.703 & 1.108 & 1.062 & 0.631 & 0.314 & 0.722 \\
\hline$A h T P P D$ & 1.452 & 0.396 & 0.197 & 1.188 & 0.750 & 0.776 & 1.035 & 1.329 & 0.744 & 0.460 & 0.256 & 0.594 \\
\hline$A h T P P I$ & 0.804 & 0.786 & 0.619 & 0.858 & 1.133 & 0.469 & 0.968 & 0.441 & 0.967 & 0.310 & 0.253 & 0.529 \\
\hline$A h T R E$ & 0.854 & 0.711 & 0.722 & 1.192 & 1.257 & 0.615 & 0.526 & 0.622 & 1.346 & 0.520 & 0.495 & 1.058 \\
\hline
\end{tabular}

$965{ }^{1}$ Calculated according to the comparative cycle threshold method (Livak and Schmittgen, 2001) using the AhACT7, AhEFla and AhPTub5 amaranth genes for 966 data normalization.

Table 2. Relative expression values ${ }^{1}$ of genes involved in trehalose synthesis and degradation in roots of four Amaranthus species subjected to two levels of water-deficit stress (moderate $[\mathrm{M}]$ and severe $[\mathrm{S}]$ ) and to subsequent recovery $([\mathrm{R}]$ ). Induced (normalized expression values $\geq 2.0$; in normal text) and repressed (normalized expression values $\leq 0.5$; in italicized text) expression values are emphasized in bold.

967 


\begin{tabular}{lccc|cccc|ccc|ccc}
\hline \multirow{2}{*}{ Gene } & \multicolumn{3}{c}{ A. hypochondriacus } & \multicolumn{3}{c}{ A. cruentus } & \multicolumn{3}{c}{ A. caudatus } & \multicolumn{3}{c}{ A. hybridus } \\
\cline { 2 - 13 } & $\mathrm{M}$ & $\mathrm{S}$ & $\mathrm{R}$ & $\mathrm{M}$ & $\mathrm{S}$ & $\mathrm{R}$ & $\mathrm{M}$ & $\mathrm{S}$ & $\mathrm{R}$ & $\mathrm{M}$ & $\mathrm{S}$ & $\mathrm{R}$ \\
\cline { 2 - 13 } AhGolS1 & $\mathbf{2 9 . 1 0 0}$ & $\mathbf{6 6 . 8 2 2}$ & 1.311 & $\mathbf{1 3 . 0 3 0}$ & $\mathbf{2 6 . 3 3 2}$ & $\mathbf{3 . 0 4 1}$ & $\mathbf{2 0 . 2 1 2}$ & $\mathbf{2 3 . 2 9 7}$ & $\mathbf{1 . 8 8 9}$ & $\mathbf{1 1 . 6 9 5}$ & $\mathbf{4 4 . 1 9 4}$ & $\mathbf{3 . 0 3 5}$ \\
AhGolS2 & $\mathbf{0 . 1 2 9}$ & $\mathbf{0 . 3 0 8}$ & $\mathbf{0 . 4 7 6}$ & $\mathbf{1 . 7 1 4}$ & 1.030 & $\mathbf{0 . 4 3 2}$ & $\mathbf{4 . 6 0 7}$ & 1.238 & 0.569 & $\mathbf{0 . 4 3 0}$ & 0.941 & 0.936 \\
AhRafS & $\mathbf{4 . 6 7 4}$ & $\mathbf{1 1 . 4 1 5}$ & 1.052 & $\mathbf{2 . 3 7 3}$ & $\mathbf{7 . 8 1 0}$ & 0.735 & $\mathbf{2 . 8 6 3}$ & $\mathbf{2 . 3 5 1}$ & 0.727 & $\mathbf{4 . 1 7 9}$ & $\mathbf{4 . 5 2 6}$ & 1.085 \\
AhStaS & 1.430 & 0.7346 & 0.595 & 1.389 & $\mathbf{1 . 7 3 5}$ & $\mathbf{0 . 4 3 1}$ & $\mathbf{1 . 5 0 2}$ & 0.862 & $\mathbf{0 . 3 0 0}$ & 1.000 & 0.885 & 0.548 \\
\hline
\end{tabular}

972
Table 3. Relative expression values ${ }^{1}$ of genes involved in the biosynthesis of raffinose family oligosaccharides in leaves of four Amaranthus species subjected to two levels of water-deficit stress (moderate $[\mathrm{M}]$ and severe $[\mathrm{S}]$ ) and to subsequent recovery ([R]). Induced (normalized expression values $\geq 2.0$; in normal text) and repressed (normalized expression values $\leq 0.5$; in italicized text) expression values are emphasized in bold.

${ }^{1}$ Calculated according to the comparative cycle threshold method (Livak and Schmittgen, 2001) using the AhACT7, AhEFla and AhBTub5 amaranth genes for data normalization. 
Table 4. Relative expression values ${ }^{1}$ of genes involved in the biosynthesis of raffinose family oligosaccharides in roots of four Amaranthus species subjected to two levels of water-deficit stress (moderate $[\mathrm{M}]$ and severe $[\mathrm{S}]$ ) and to subsequent recovery ([R]). Induced (normalized expression values $\geq 2.0$; in normal text) and repressed (normalized expression values $\leq 0.5$; in italicized text) expression values are emphasized in bold.

\begin{tabular}{lccc|cccc|cccccc}
\hline \multirow{2}{*}{ Gene } & \multicolumn{3}{c}{ A. hypochondriacus } & \multicolumn{3}{c}{ A. cruentus } & \multicolumn{3}{c}{ A. caudatus } & \multicolumn{3}{c}{ A. hybridus } \\
& \cline { 2 - 12 } & $\mathrm{M}$ & $\mathrm{S}$ & $\mathrm{R}$ & $\mathrm{M}$ & $\mathrm{S}$ & $\mathrm{R}$ & $\mathrm{M}$ & $\mathrm{S}$ & $\mathrm{R}$ & $\mathrm{M}$ & $\mathrm{S}$ & $\mathrm{R}$ \\
\cline { 2 - 13 } AhGolS1 & $\mathbf{2 2 . 2 0 2}$ & $\mathbf{1 3 6 . 7 4 4}$ & 0.819 & $\mathbf{1 4 . 7 4 5}$ & $\mathbf{2 4 8 . 8 5 7}$ & $\mathbf{2 . 1 2 8}$ & $\mathbf{1 8 . 0 1 8}$ & $\mathbf{7 5 . 9 3 2}$ & 1.088 & $\mathbf{1 7 . 0 0 9}$ & $\mathbf{3 7 . 6 9 1}$ & $\mathbf{1 . 8 7 0}$ \\
AhGolS2 & 0.673 & $\mathbf{3 . 4 7 1}$ & 0.261 & $\mathbf{2 . 6 9 7}$ & $\mathbf{3 . 3 4 5}$ & 1.198 & $\mathbf{2 . 4 0 1}$ & $\mathbf{2 . 5 3 9}$ & 1.124 & $\mathbf{2 . 3 5 5}$ & $\mathbf{2 . 3 2 8}$ & 0.696 \\
AhRafS & $\mathbf{3 . 4 2 6}$ & $\mathbf{1 4 . 9 8 1}$ & 1.270 & $\mathbf{1 . 7 9 5}$ & $\mathbf{1 5 . 1 9 0}$ & 1.008 & $\mathbf{2 . 2 6 8}$ & $\mathbf{5 . 4 2 6}$ & 0.539 & $\mathbf{3 . 6 9 9}$ & 1.407 & 0.510 \\
AhStaS & $\mathbf{2 . 9 6 0}$ & $\mathbf{6 . 2 1 9}$ & 1.378 & $\mathbf{6 . 5 8 3}$ & $\mathbf{5 . 1 2 6}$ & $\mathbf{1 . 5 5 3}$ & $\mathbf{5 . 5 2 5}$ & $\mathbf{5 . 0 8 9}$ & $\mathbf{2 . 3 8 1}$ & $\mathbf{2 . 9 4 3}$ & $\mathbf{2 . 7 5 8}$ & 1.034 \\
\hline
\end{tabular}

${ }^{1}$ Calculated according to the comparative cycle threshold method (Livak and Schmittgen, 2001) using the AhACT7, AhEFla and AhBTub5 amaranth genes for data normalization. 
Table 5. Relative expression values ${ }^{1}$ of abscisic acid (ABA) marker genes in leaves of four Amaranthus species subjected to two levels of waterdeficit stress (moderate $[\mathbf{M}]$ and severe $[\mathbf{S}]$ ) and to subsequent recovery $([\mathbf{R}]$ ). Induced (normalized expression values $\geq 2.0$; in normal text) and repressed (normalized expression values $\leq 0.5$; in italicized text) expression values are emphasized in bold.

\begin{tabular}{|c|c|c|c|c|c|c|c|c|c|c|c|c|}
\hline \multirow[t]{2}{*}{ Gene } & \multicolumn{3}{|c|}{ A. hypochondriacus } & \multicolumn{3}{|c|}{ A. cruentus } & \multicolumn{3}{|c|}{ A. caudatus } & \multicolumn{3}{|c|}{ A. hybridus } \\
\hline & M & $\mathrm{S}$ & $\mathrm{R}$ & M & $\mathrm{S}$ & $\mathrm{R}$ & $\mathrm{M}$ & $\mathrm{S}$ & $\mathrm{R}$ & M & $\mathrm{S}$ & $\mathrm{R}$ \\
\hline$A h A B I 5$ & 2.005 & 3.047 & 2.202 & 1.937 & 4.014 & 0.726 & 3.244 & 1.469 & 1.317 & 2.437 & 2.590 & 2.507 \\
\hline AhDREB & 5.300 & 8.754 & 3.867 & 0.858 & 1.251 & 0.631 & 1.655 & 0.921 & 0.739 & 0.665 & 1.689 & 1.159 \\
\hline AhRAB18 & 0.776 & 0.789 & 0.963 & 0.885 & 0.843 & 0.350 & 1.642 & 1.233 & 0.861 & 0.502 & 1.815 & 1.052 \\
\hline AhLEA14 & 21.284 & 64.530 & 5.835 & 16.518 & 31.398 & 2.136 & 49.051 & 120.856 & 4.553 & 16.745 & 46.504 & 2.539 \\
\hline
\end{tabular}

Calculated according to the comparative cycle threshold method (Livak and Schmittgen, 2001) using the AhACT7, AhEFla and AhBTub5 amaranth genes for data normalization.

1003

1004

1005

1006

1007

1008

1009

1010

1011

1012 
Table 6. Relative expression values ${ }^{1}$ of abscisic acid (ABA) marker genes in roots of four Amaranthus species subjected to two levels of waterdeficit stress (moderate $[\mathbf{M}]$ and severe $[\mathbf{S}]$ ) and to subsequent recovery $([\mathbf{R}])$. Induced (normalized expression values $\geq 2.0$; in normal text) and repressed (normalized expression values $\leq 0.5$; in italicized text) expression values are emphasized in bold.

\begin{tabular}{lccc|cccc|cccccc}
\hline \multirow{2}{*}{ Gene } & \multicolumn{3}{c}{ A. hypochondriacus } & \multicolumn{3}{c}{ A. cruentus } & \multicolumn{3}{c}{ A. caudatus } & \multicolumn{3}{c}{ A. hybridus } \\
& \cline { 2 - 12 } & $\mathrm{M}$ & $\mathrm{S}$ & $\mathrm{R}$ & $\mathrm{M}$ & $\mathrm{S}$ & $\mathrm{R}$ & $\mathrm{M}$ & $\mathrm{S}$ & $\mathrm{R}$ & $\mathrm{M}$ & $\mathrm{S}$ & $\mathrm{R}$ \\
\cline { 2 - 13 } AhABI5 & $\mathbf{1 3 . 8 7 0}$ & $\mathbf{2 2 . 7 5 4}$ & $\mathbf{1 8 . 9 7 9}$ & $\mathbf{5 . 9 0 3}$ & $\mathbf{8 . 4 4 6}$ & $\mathbf{1 . 8 5 5}$ & $\mathbf{2 . 3 0 7}$ & $\mathbf{1 . 6 3 2}$ & 0.977 & $\mathbf{0 . 4 2 6}$ & 1.062 & $\mathbf{0 . 3 9 2}$ \\
AhDREB & $\mathbf{9 . 9 5 1}$ & $\mathbf{1 6 . 0 0 9}$ & $\mathbf{1 6 . 0 3 4}$ & $\mathbf{2 . 6 0 7}$ & $\mathbf{5 . 0 7 7}$ & $\mathbf{1 . 7 9 3}$ & $\mathbf{3 . 0 5 5}$ & $\mathbf{2 . 0 0 7}$ & 0.859 & 1.199 & 1.491 & 0.913 \\
AhRAB18 & $\mathbf{5 . 6 4 1}$ & $\mathbf{5 . 7 3 5}$ & $\mathbf{1 4 . 4 4 5}$ & 1.477 & $\mathbf{2 . 3 1 8}$ & 1.016 & 0.978 & 1.093 & 0.729 & 0.548 & $\mathbf{0 . 4 1 8}$ & 1.121 \\
AhLEA14 & $\mathbf{4 . 4 6 4}$ & $\mathbf{1 2 . 8 2 9}$ & $\mathbf{1 . 6 2 9}$ & $\mathbf{2 . 3 5 6}$ & $\mathbf{6 . 9 1 6}$ & 0.898 & $\mathbf{1 . 7 6 1}$ & $\mathbf{7 . 4 0 8}$ & 1.231 & $\mathbf{3 . 8 8 0}$ & $\mathbf{5 . 1 8 3}$ & 0.761 \\
\hline
\end{tabular}

${ }^{1}$ Calculated according to the comparative cycle threshold method (Livak and Schmittgen, 2001) using the AhACT7, AhEF1a and AhBTub5 amaranth genes for data normalization. 


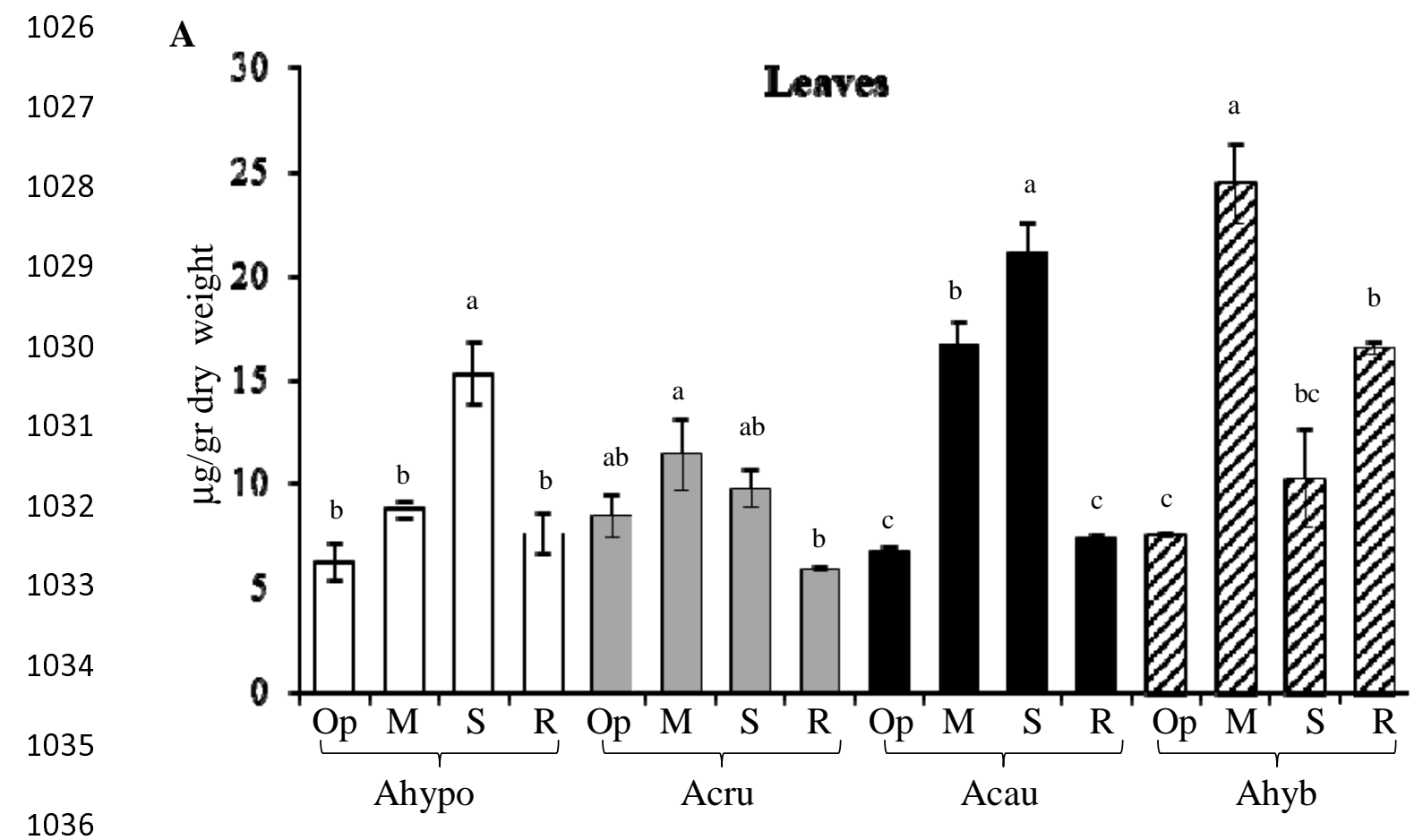

1037

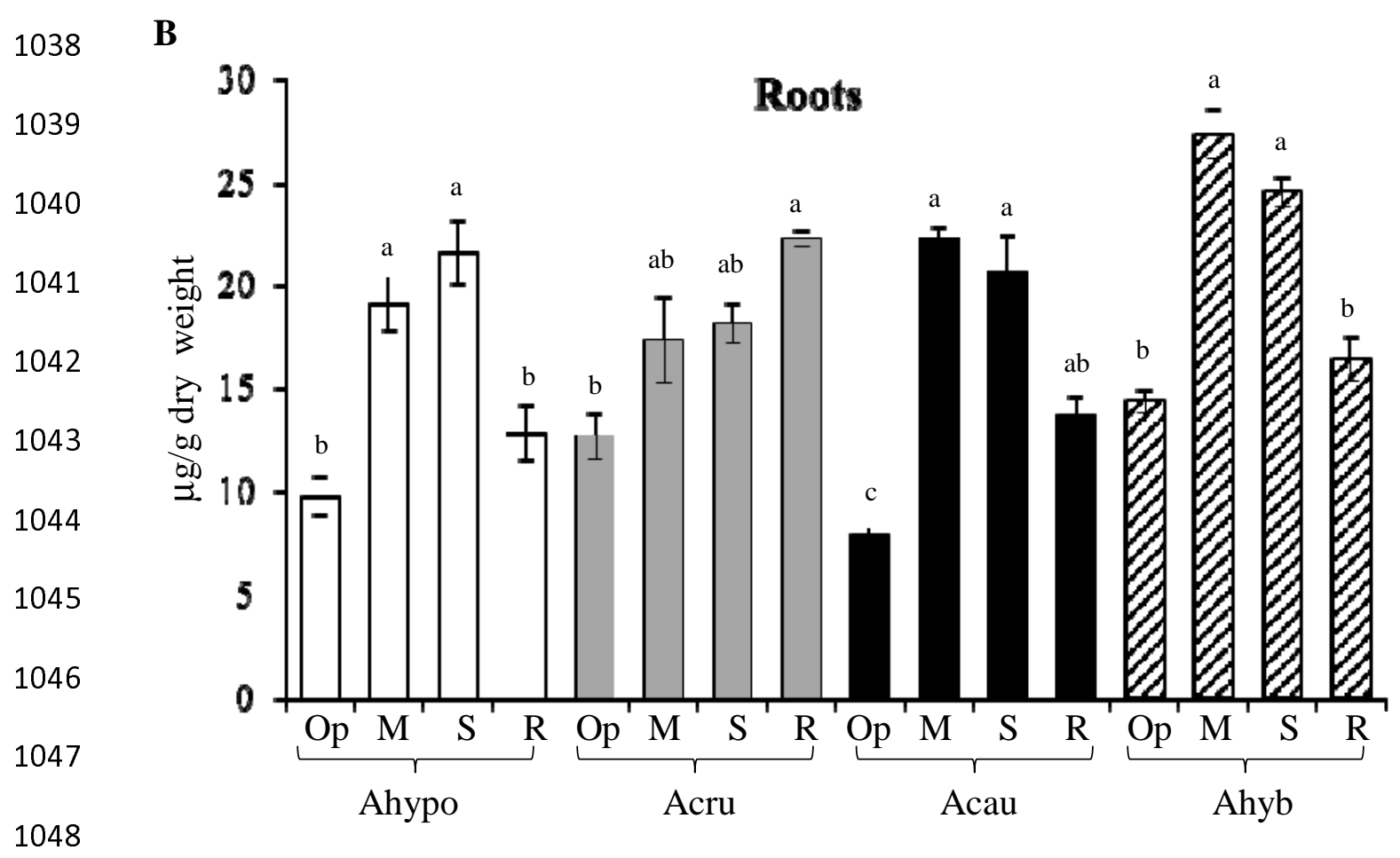

1049

1050

Fig. 1 
A

1052

1053

1054

1055

1056

1057

B

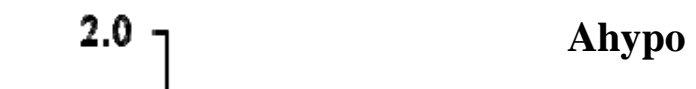

$\square \mathrm{Op}$

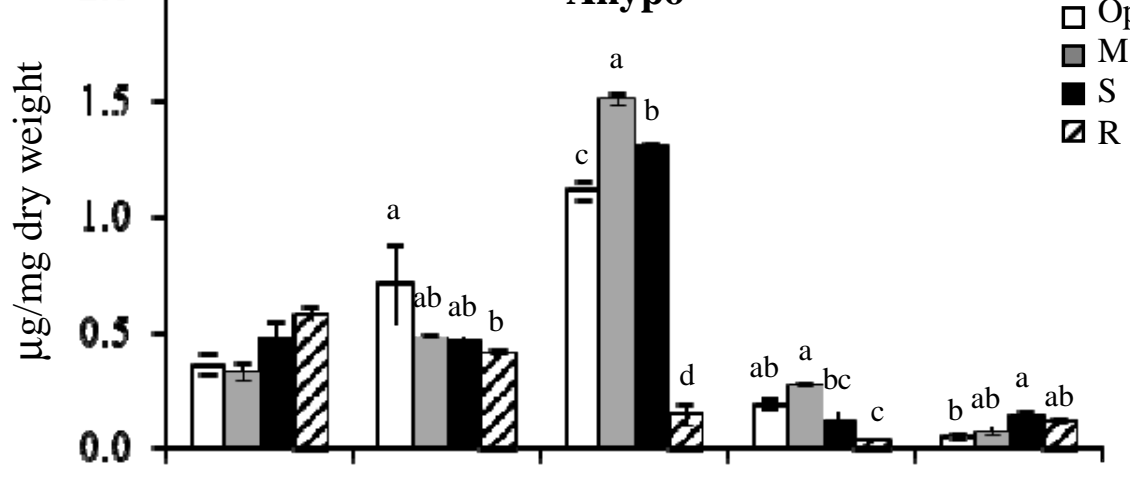

1058

1059

1060

1061

1062

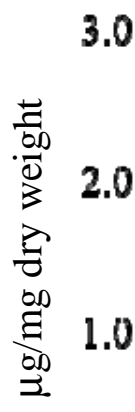

1062

0.0

C

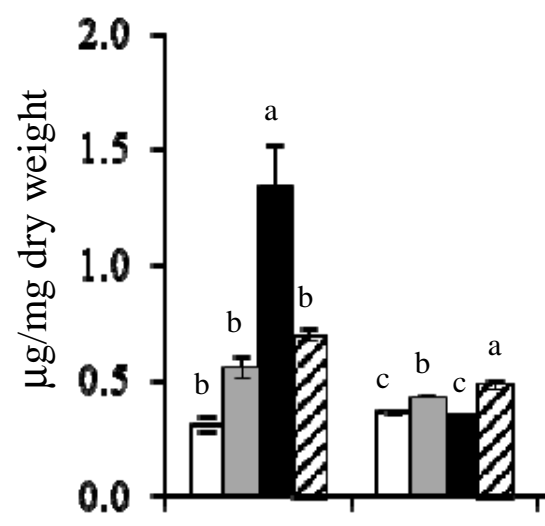

Acau

1064

1065

1066

1067

1068

1069

1070

D

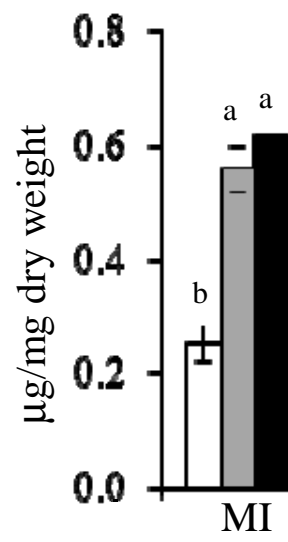

1075

1071

1072

1073

1074
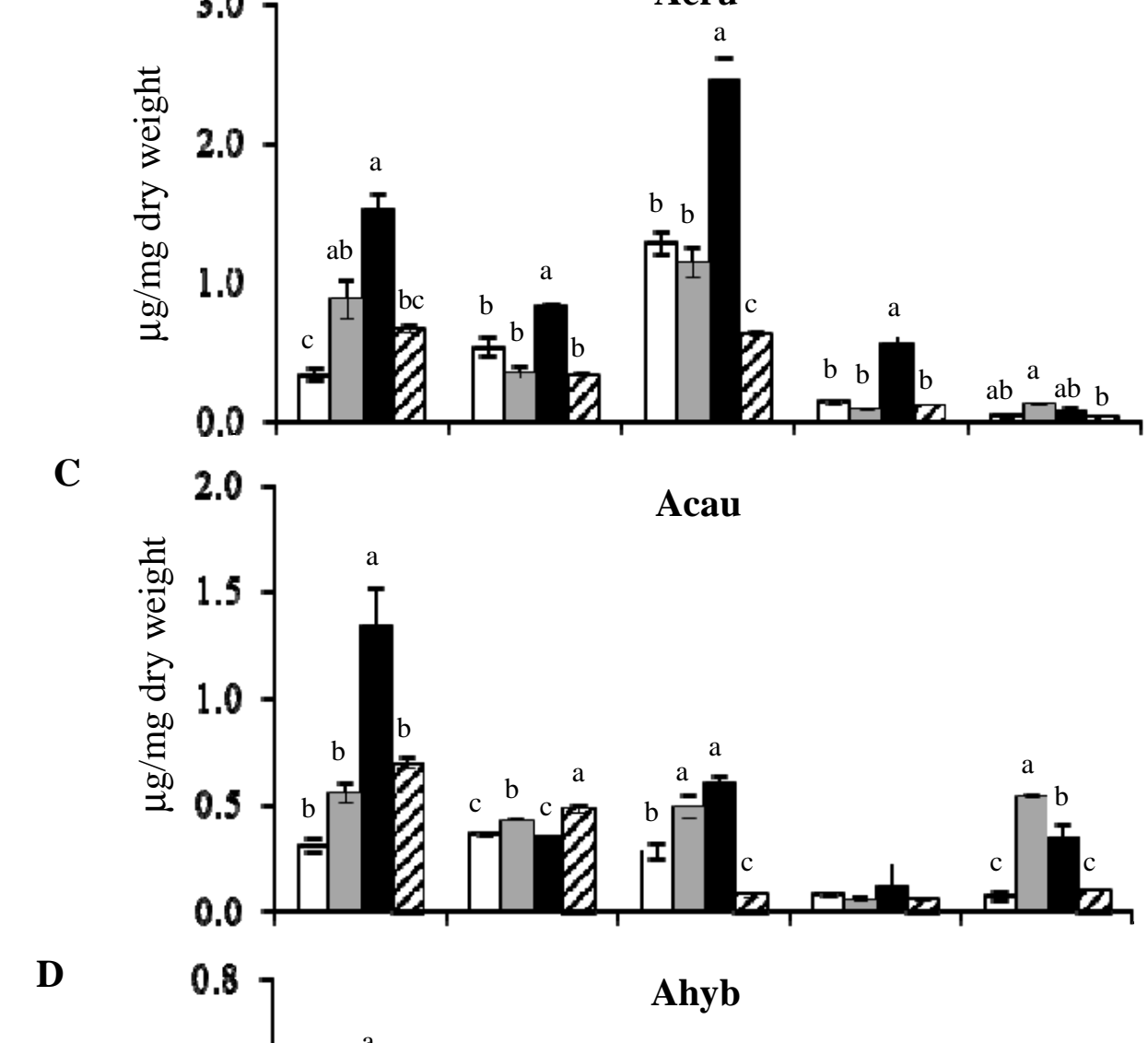
1076

1077

1078

1079

1080

1081

1082

1083

1084

1085

1086

1087

1088

1089

1090

1091

1092

1093

1094

1095

1096

1097

1098

1099

1100
A

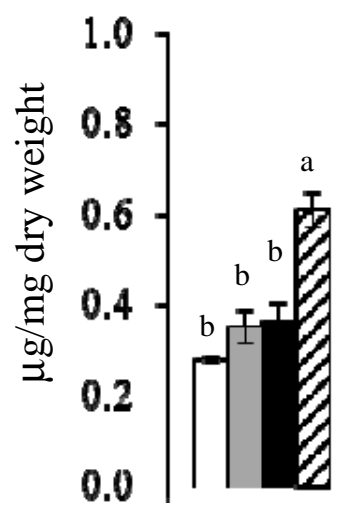

B

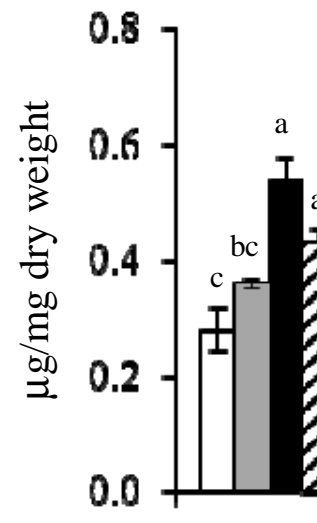

C

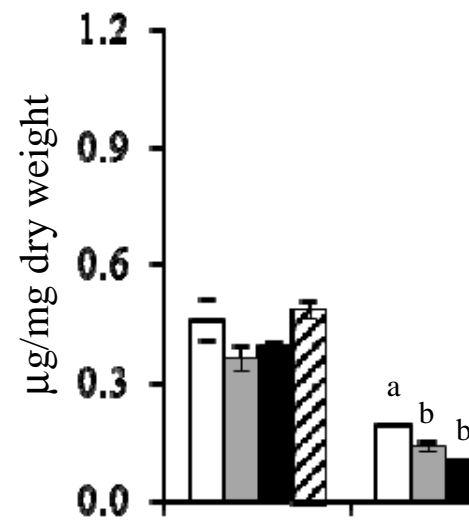

Ahypo

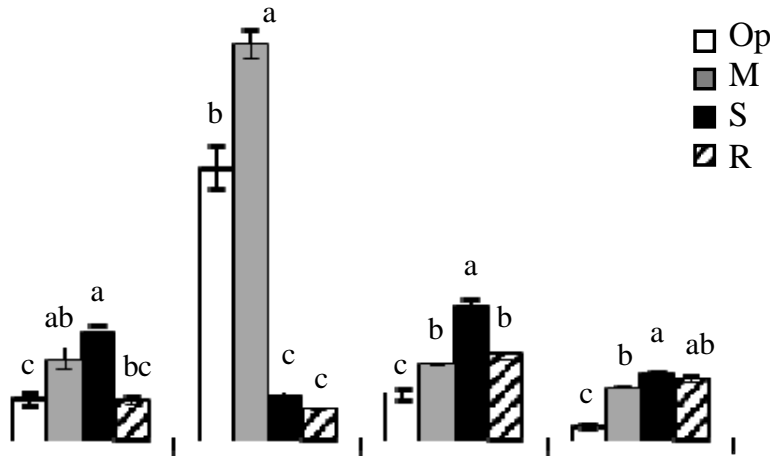

Acru

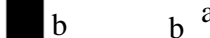


A

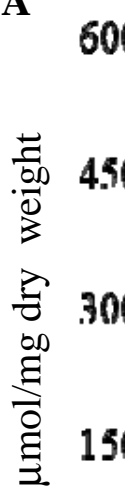

1113

1114

1115

1116

1117

1118

1120

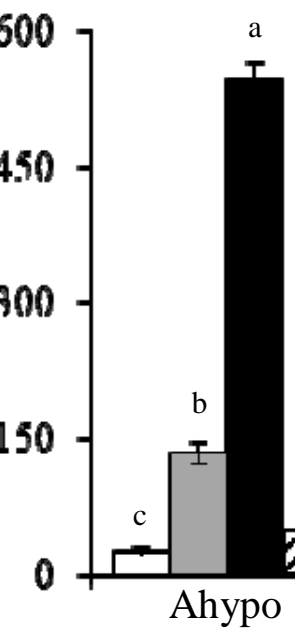

a

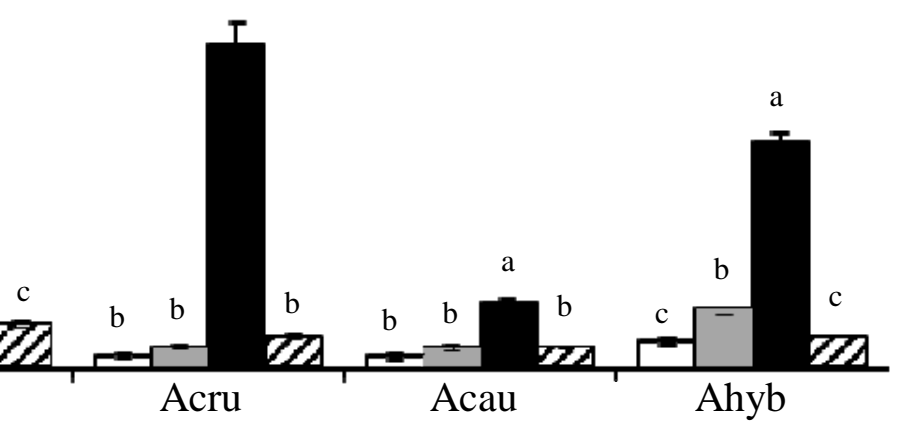

\section{Leaves}

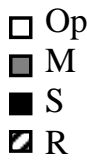

1121 

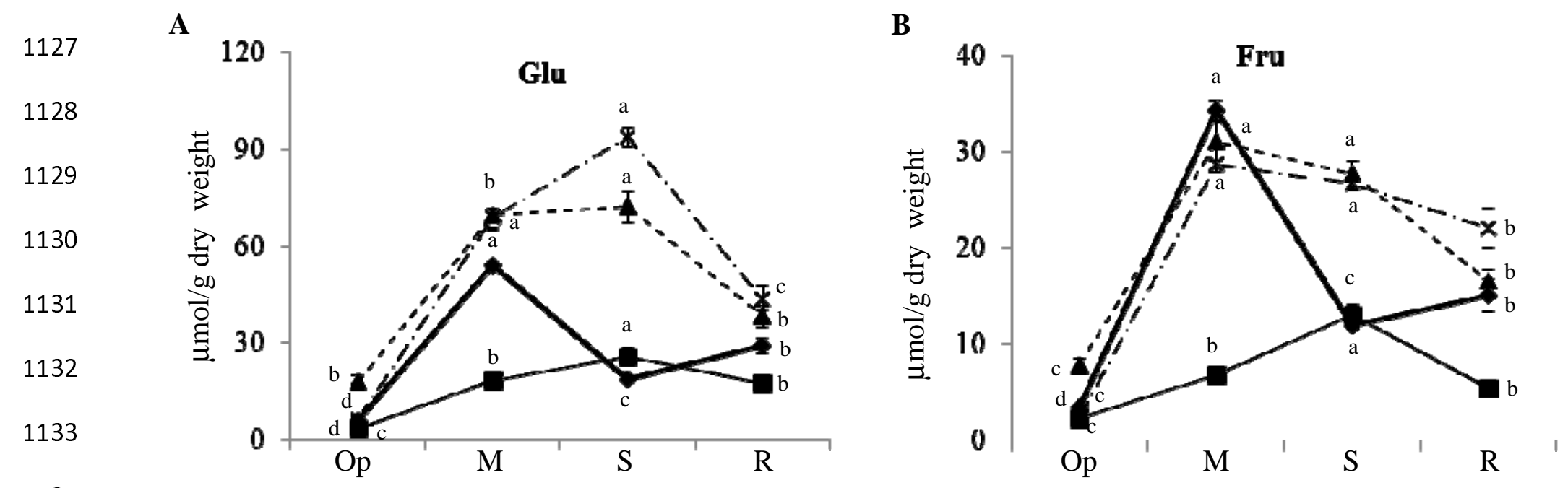

1134

1135

1136

C

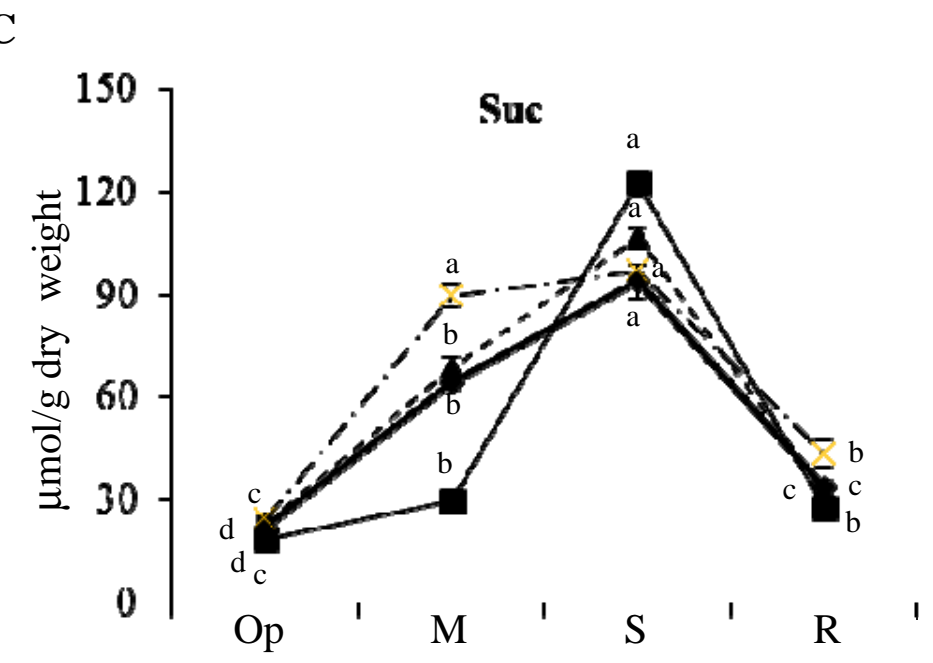

D
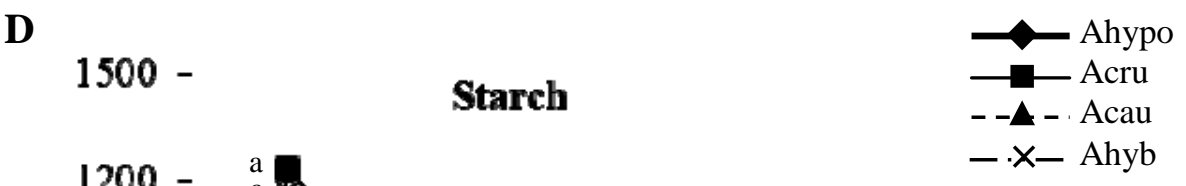

1137

1138

1139

1140

1141

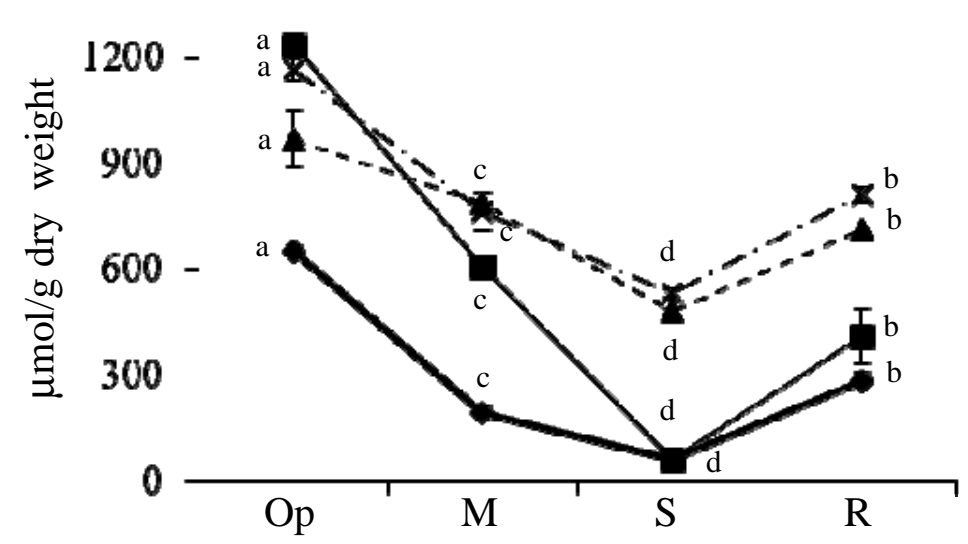

Fig. 5 

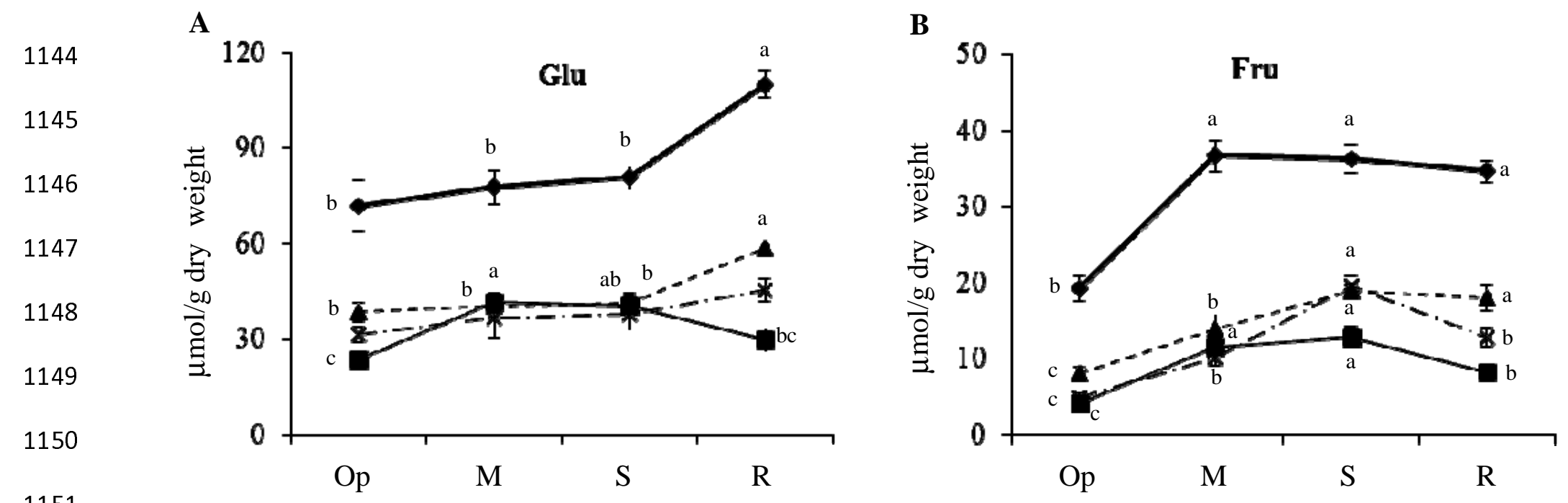

1151

$$
\text { C }
$$
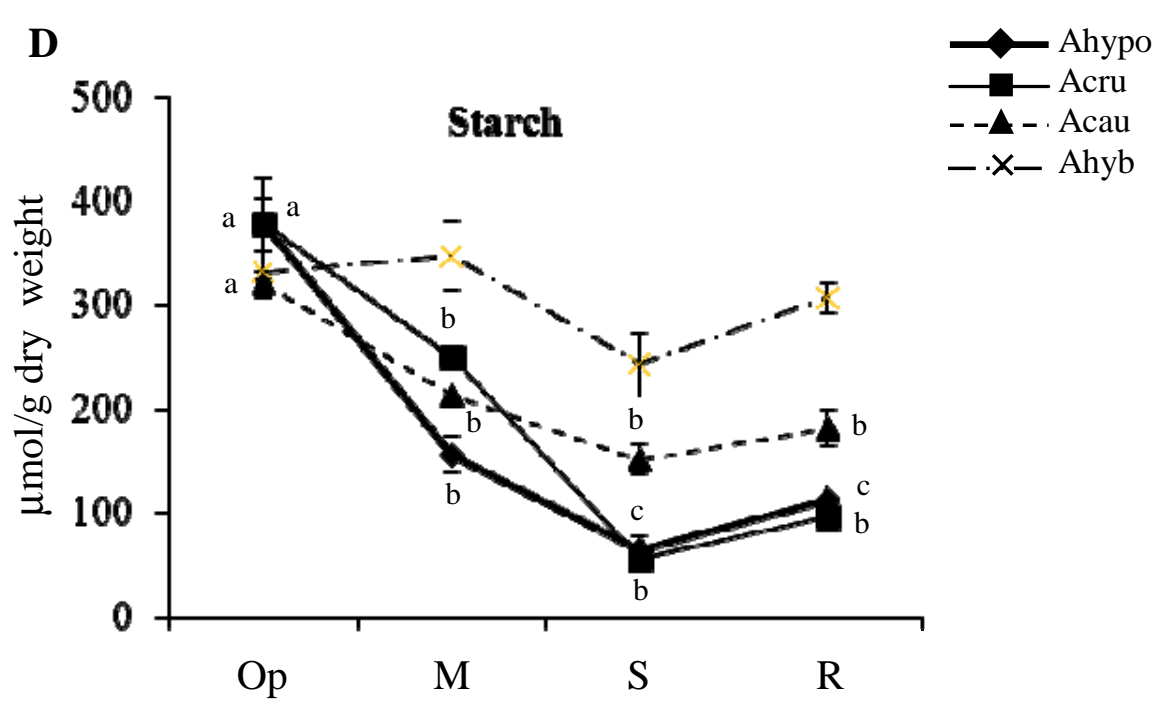

1153

1154

1155

1156

1157

1158

1159

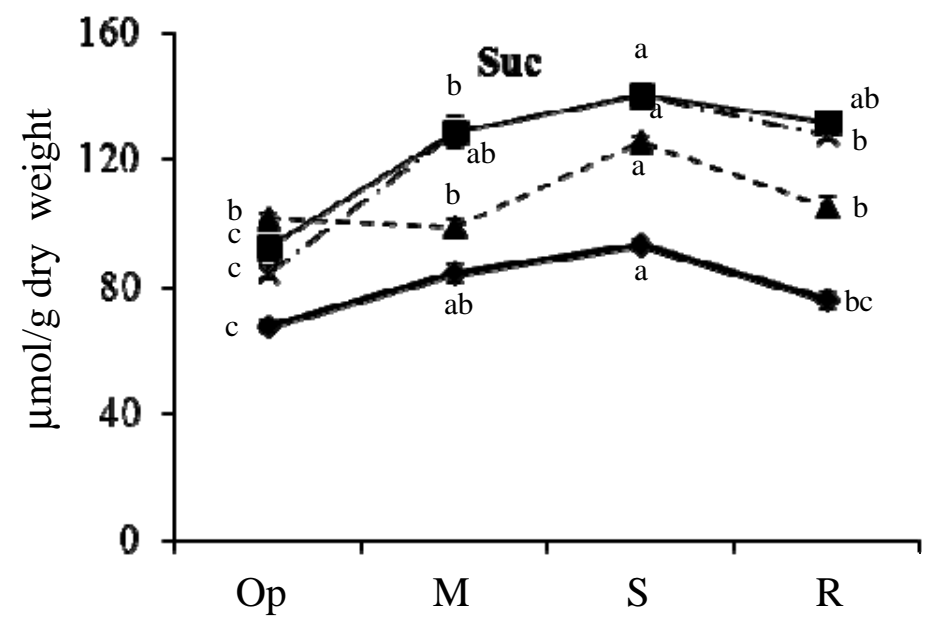

Fig. 6 
A

1164

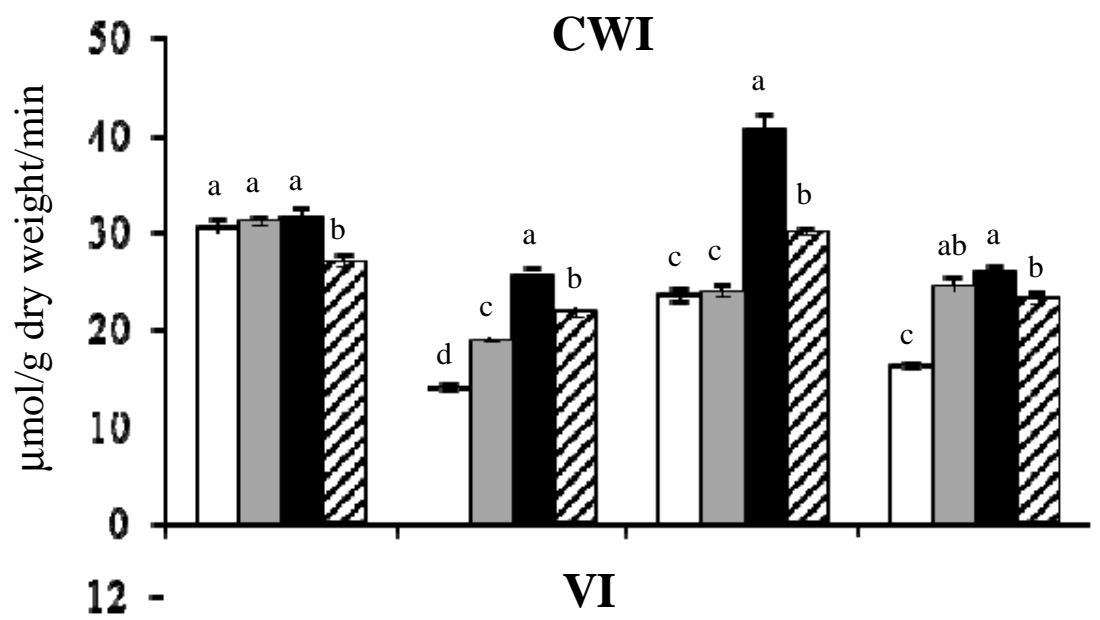

1170

1171

1172

1173

1174

1175

1176

1177

1178

1179

1180

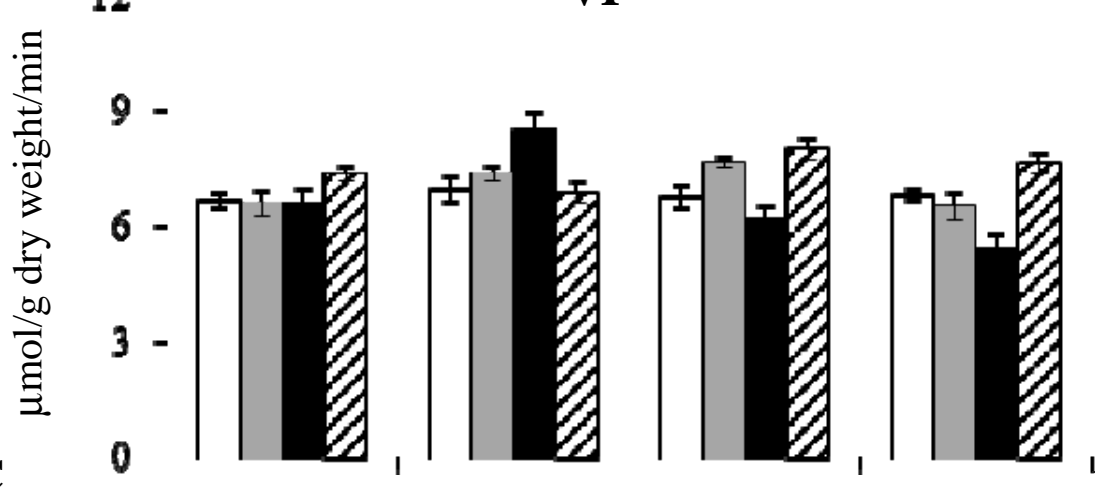

1181

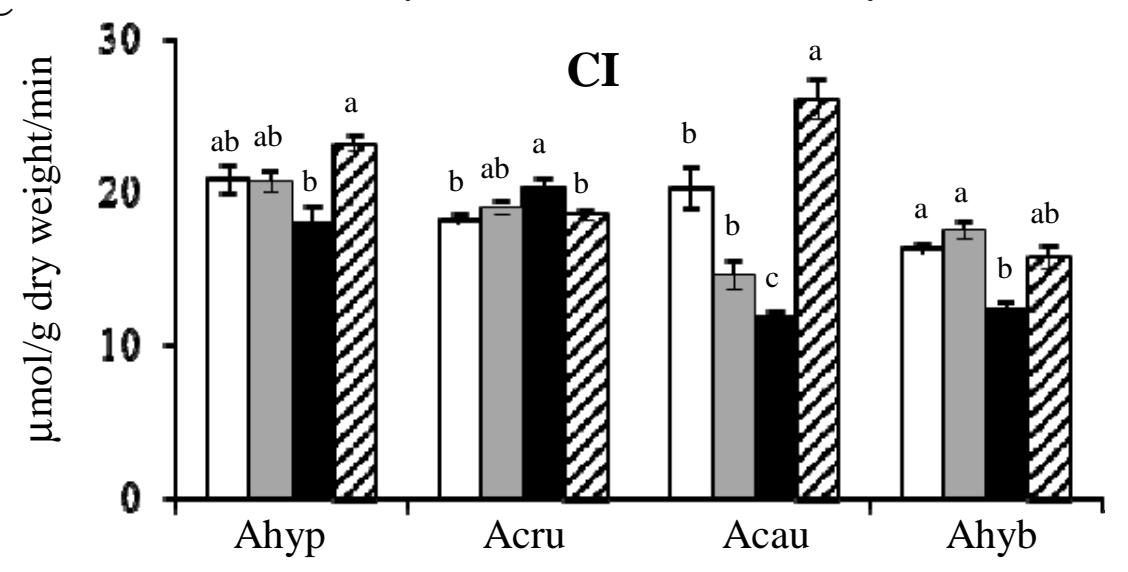

1182

1183 
A

1189

1190

1191

1192

1193

1194

1195

1196

1197

1198

1199

1200

1201

1202

1203

1204

1205

1206

1207

1208

1209

B

C
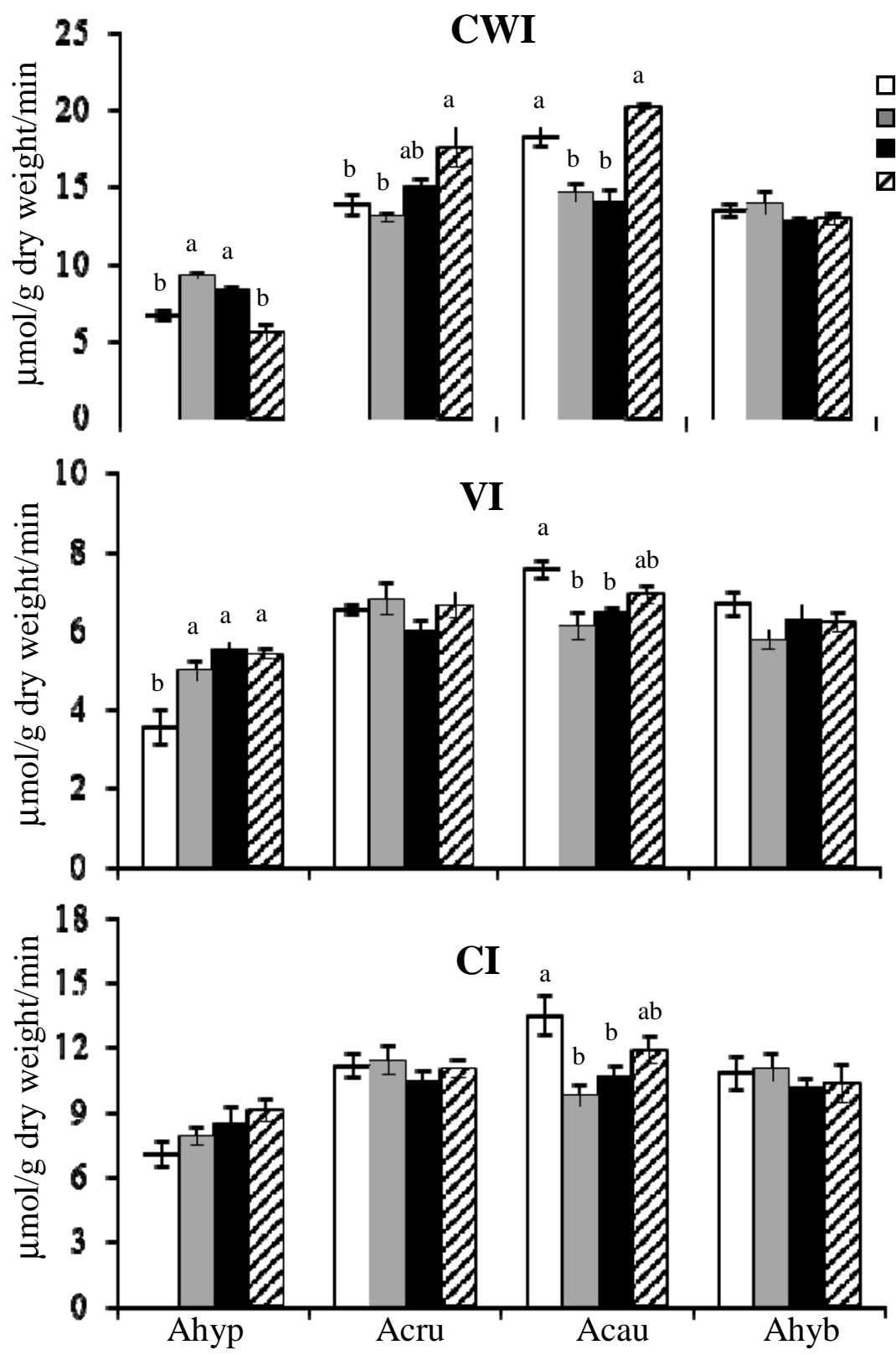

\section{CWI}

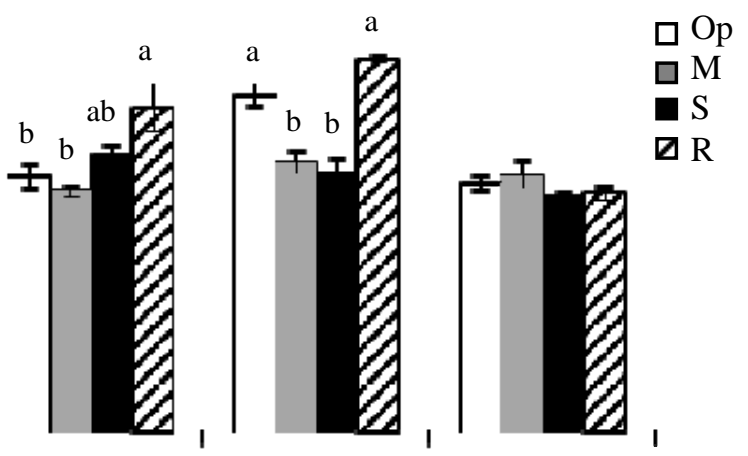

$\square \mathrm{Op}$

$\mathrm{S}$

$\mathrm{R}$ 


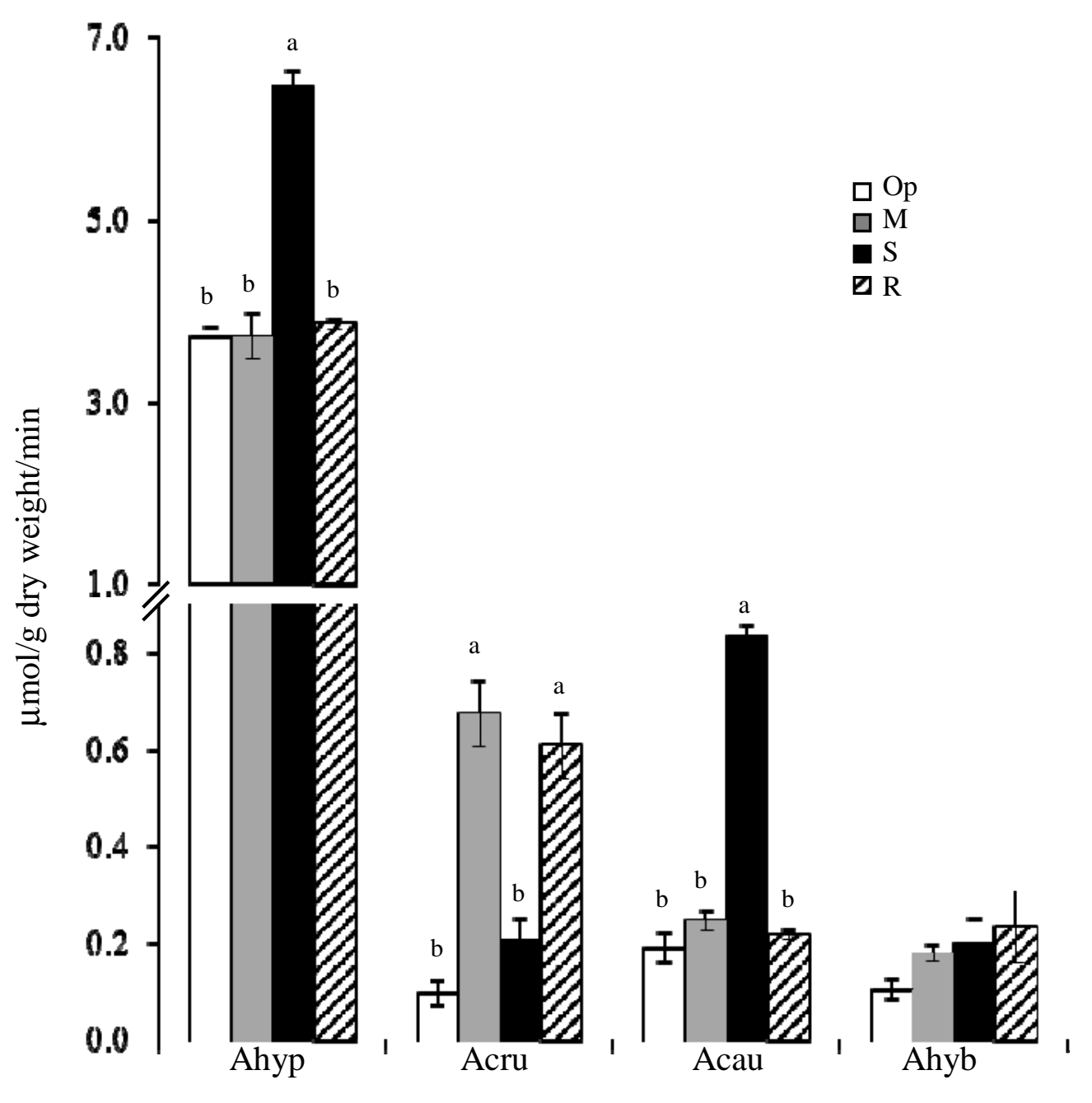

1230

1231 
1238

1239

1240

1241

1242

1243

1244

1245

1246

1247

1248

1249

1250

1251

1252

1253

1254

1255

1256

1257
A
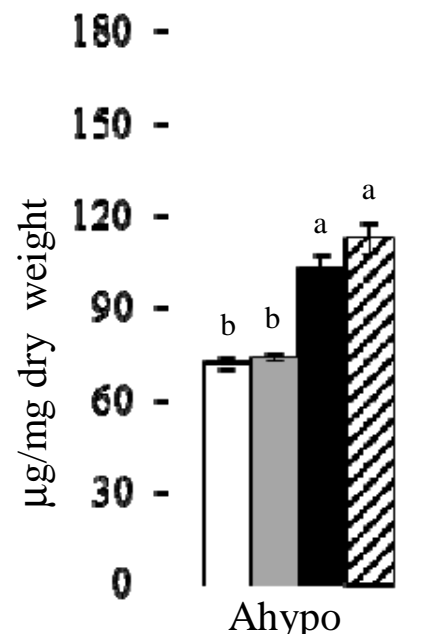

B

100

\section{Leaves}

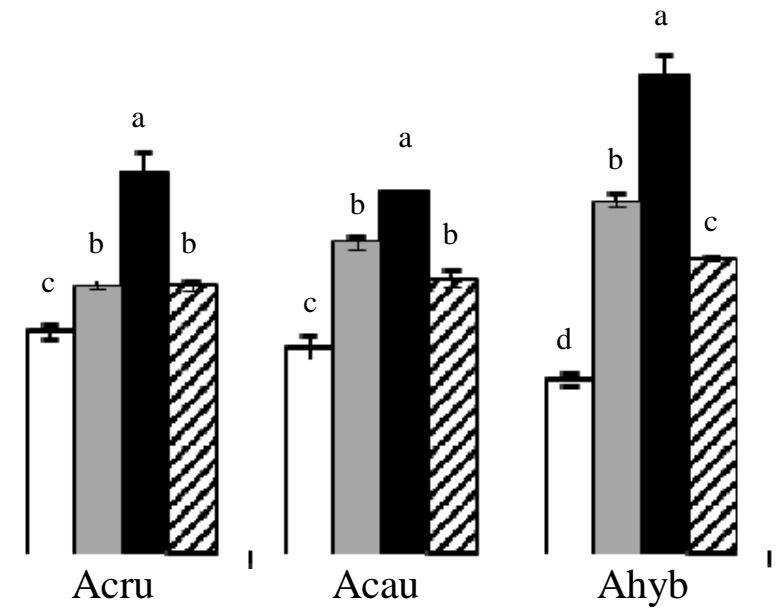

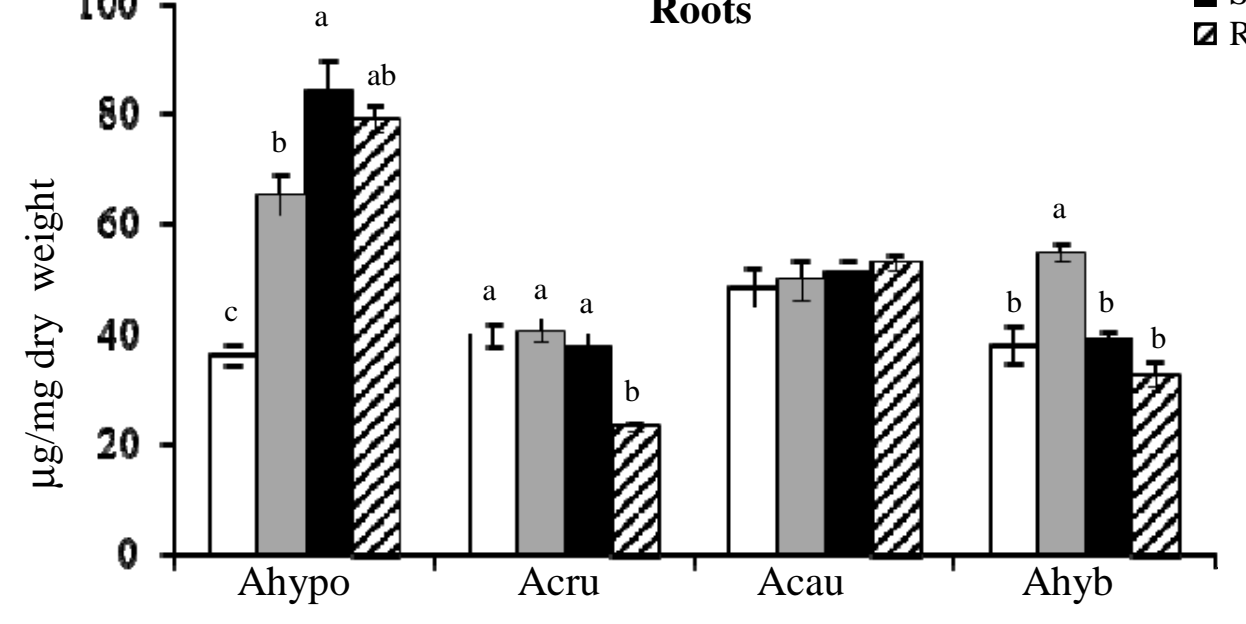

$\mathrm{M}$

$\mathrm{S}$

$\mathrm{R}$

Fig. 10

1259 